\title{
Numerical Evaluation of the Performances of the Ventilation System in a Blast Furnace Casthouse
}

\section{Hui Wang ( $\sim$ Wanghui@cribc.com )}

State Key Laboratory of Iron and Steel Industry Environment Protection

\section{Tianying Wang}

State Key Laboratory of Iron and Steel Industry Environment Protection

liuchan Liu

School of Environment Science and Engineer,Tianjin Universuty

Zhengwei Long

School of Environment Science and Engineering,Tianjin University

Pu Zhang

State Key Laboratory of Iron and Steel Industry Environment Protection

\section{Research Article}

Keywords: Blast furnace cast house, dust, concentration distribution, field test, numerical simulation, Industrial ventilation

Posted Date: March 8th, 2021

DOl: https://doi.org/10.21203/rs.3.rs-281751/v1

License: (c) (i) This work is licensed under a Creative Commons Attribution 4.0 International License. Read Full License 


\section{Numerical evaluation of the performances of the ventilation system} in a blast furnace casthouse

Hui Wang ${ }^{1,2,3}$, Tianying Wang ${ }^{1,2,3}$, Liuchan Liu ${ }^{4}$, Zhengwei Long ${ }^{4}$, Pu Zhang ${ }^{1,2,3}$

${ }^{1}$ State Key Laboratory of Iron and Steel Industry Environmental Protection, Beijing, China.

${ }^{2}$ Central Research Institute of Building and Construction Co., Ltd, MCC Group, Beijing, China.

${ }^{3}$ Energy Conservation and Environment Protection Co., Ltd, MCC Group, Beijing, China.

${ }^{4}$ Tianjin Key Laboratory of Indoor Air Environmental Quality Control, School of Environmental

Science and Engineering, Tianjin University, Tianjin, China

\section{*Correspond: Wanghui@cribc.com}

\section{Abstract}

The blast furnace casthouse is a typical heavy-polluting factory building of a steel enterprise. During the tapping process and the taphole opening, the dust concentration in the factory building's workroom can reach tens of thousands $\mathrm{mg} / \mathrm{m}^{3}$. Over time, the air pollutants in the workplace can have unwanted consequences on employees' health. This paper selected a typical blast furnace tapping workshop and measured on-site the characteristics of the wind speed distribution, temperature distribution, and soot concentration distribution during the taping period. A numerical simulation model was established to analyze the taphole smoke exhaust system's performance based on computational fluid dynamics. The findings are: the velocity, temperature, and smoke density distributions in the workplace were very uneven, and the thermal comfort of the workers' area was relatively poor. Also, the concentration of PM2.5 was mostly below $80 \mu \mathrm{g} / \mathrm{m}^{3}$. Besides, due to the plant's on-site measurement, real data was obtained for numerical simulation verification, making the evaluation of the entire plant's ventilation performance more reliable. Hence, this article's finding provides a scientific basis for optimizing the air distribution in the blast furnace cast house's workplace.

Key words: Blast furnace cast house; dust; concentration distribution; field test; numerical simulation; Industrial ventilation.

\section{Introduction}

China is now the top steel producer globally (Tang et al,2020). The iron and steel industry is a major air pollutant emitter and has become China's largest industrial PM emission source (Wang et al,2019). In order to deal with air pollution, iron and steel companies must improve flue gas management. Besides, the steel plant is a high temperature and dusty plant, and steelworkers are particularly prone to occupational health problems. Biswas et al. (2014) found that $91.66 \%$ of 213 workers may have bronchial asthma and $88.75 \%$ of chronic bronchitis after long-term exposure. Excessive heat exposure causes workers to experience sweating, thirst, insomnia, fatigue, and muscle discomfort (Krishnamurthy et al,2017; Fahed et al,2018). Therefore, it is significant to improve the smoke and dust control and the plant's ventilation and heat 
exchange efficiency.

In response to the above problems, the ventilation of industrial plants is generally used to eliminate various gas and dust pollutants generated during the production process; to ensure that workers are in a healthy production environment ( $\mathrm{Li}$ et al,2016), and a sound airflow organization system is instituted to reduce fugitive emissions of smoke and dust. Since the development of computational fluid dynamics, numerical simulation has gradually become one way to study airflow organization in industrial plants. Zhang et al. (2017) research shows that CFD can be effective for the verification of ventilation design schemes, and field measurements are more realistic and representative for the acquisition of model boundary conditions. Wang et al. (2013) used CFD to study the key to high-temperature dust control in steel plants and gave an optimal design approach for engineering verification. Xue et al. (2011) used the CFD method to perform a numerical simulation of natural ventilation in a workshop with solar chimneys; it was verified that the model is reliable by comparing it with experimental data in other kinds of literature. Similarly, Su et al. (2011) used computational fluid dynamics (CFD) to simulate the natural ventilation in the steel company workshop numerically. They verified the numerical results with experimental data from other documents to improve the workshop's airflow organization based on numerical calculations. Likewise, Ma et al. (2015) utilized Fluent in the process of tapping in a workshop with a ferroalloy furnace, the software obtains the concentration distribution and residence time of the particles through simulations under different wind directions and wind speeds; the study also used the experimental data of others for verification. Wang et al. (2021) established a two-phase flow model in the iron yard plant using a numerical simulation method for the diffusion and capture process of hightemperature smoke and dust through CFD, and explored the critical factors of particle capture in the iron yard. In related literature, Based on the orthogonal experiment and CFD method, Yang et al. (2015) obtained the best solution by comparing and analyzing the airflow distribution of steel workshops with different window structures. Cao et al. (2020) proposed the MVV ventilation system, and based on CFD simulation to verify the ventilation effect of this method in industrial plants with large aspect ratio and high pollution emission. Moreover, Chen et al. (2020) used computational fluid dynamics and building energy simulation (BES) to compare the energy consumption of displacement ventilation systems, hybrid ventilation systems and existing ventilation systems in factories. In another study, in his research on the performance of underfloor air supply displacement ventilation, Lau et al. (2006) conducted experiments in a fullscale environment and obtained more realistic data, which verified the correctness of the CFD method. Wiriyasart et al. (2019) used computational fluid dynamics (CFD) analysis and field tests to study indoor air quality and heat distribution in a workshop with multiple heat sources, the results showed the expected temperature and wind speed in the workshop was consistent with the experimental results. Moreover, a related study by Zhang et al. (2016) developed a method that combines computational fluid dynamics (CFD) simulation with field measurements. Interestingly, all these studies' analyses 
proved that CFD could better simulate the flow field and particulate matter distribution in industrial plants. Field tests can provide more reliable data to verify the CFD model and provide help for ventilation performance research. However, despite this much research on industrial plants' airflow organization, there is still a vacuum in the field test and numerical simulation of real iron casting plants.

As a means of minimizing this vacuity, the article takes a blast furnace tapping place. It conducts field tests on the ventilation wind speed and wall temperature of the workshop's doors and windows, as well as the velocity field, temperature field and particle concentration field in the workshop, and obtain the distribution data and boundaries condition data during the tapping period. The paper established the computational fluid dynamics simulation model including the flow, temperature distribution, and particle propagation models to analyze the workshop's existing ventilation system's performance. The simulation analysis was done using the test boundary data, and the test data verified the model. The analysis reveals the iron removal workshop rules and provides a scientific basis for improving the ventilation system.

\section{Field Measurements}

\subsection{The cast house state}

This paper's research object is a blast furnace tapping house of a steel plant in Hubei, whose crude steel production capacity is about 4 million tons/year. There are two $2600 \mathrm{~m} 3$ medium-sized blast furnaces in the iron and steel plant. In this paper, the tapping platform of blast furnace No. 1 is selected as the primary research object. No. 1 casting yard workshop is $85 \mathrm{~m}$ long, $63 \mathrm{~m}$ wide, $25 \mathrm{~m}$ high, and covers about $5355 \mathrm{~m}^{2}$. The specific content is shown in Figure 1. The plant's primary ventilation method is natural ventilation; air enters the plant from the bottom door windows and is naturally discharged from the top skylight. A small number of dust hoods are arranged near the dust production point for mechanical ventilation and dust removal. Furthermore, the blast furnace tapping yard is equipped with three taps. These three taps worked continuously during regular operation, with an average tapping time of $2 \mathrm{hrs}$ daily.

The plant's main dust-producing points are tapholes, iron ditch, skimmer, slag ditch, mobile swing nozzle. Aiming at these smoke and dust emission points, a dust hood is arranged above each tap hole for mechanical ventilation to collect a large amount of smokes and dust emitted from the tap hole and the front iron trough; surfaces of the trough platform are all covered and flattened. The iron ditch and the slag ditch are covered with iron plates to prevent the diffusion of particulate matter into the workshop. The skimmer's side suction hood and the dust removal hood of the swing nozzle are arranged under the platform to capture a large amount of smoke and dust generated during molten iron flow. This paper focuses mainly on the ventilation and dust removal above the platform of the iron casting plant. The skimmer's side suction hood and the swing nozzle's dust removal hood under the platform are not in the research scope. 

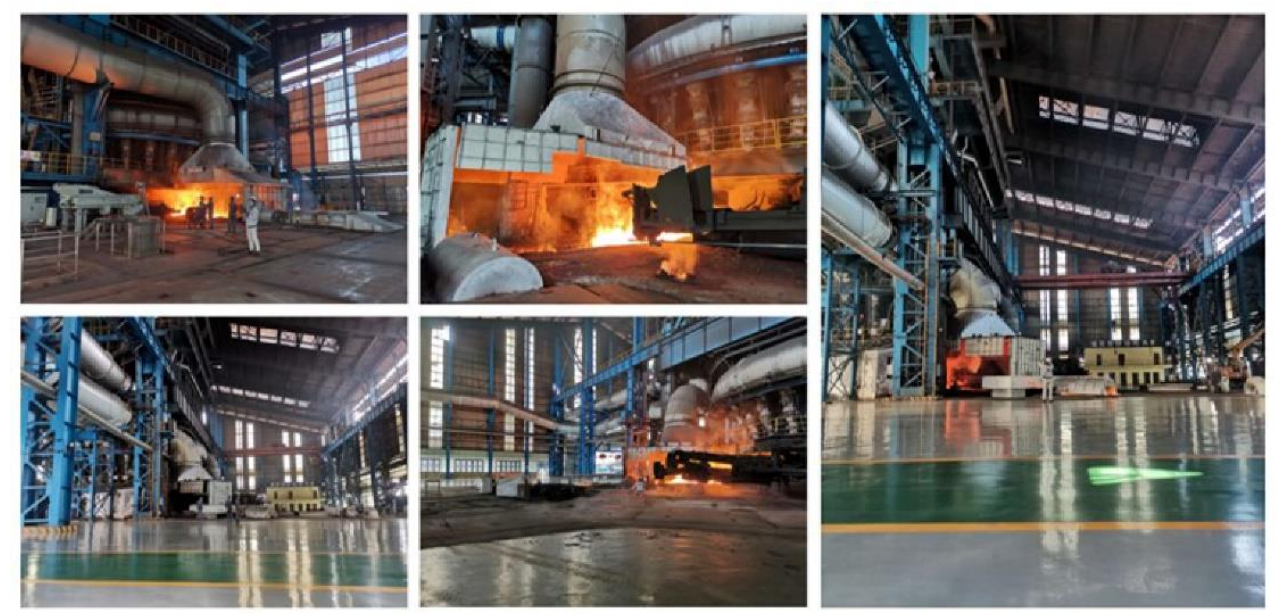

(a) Interior view of the workshop

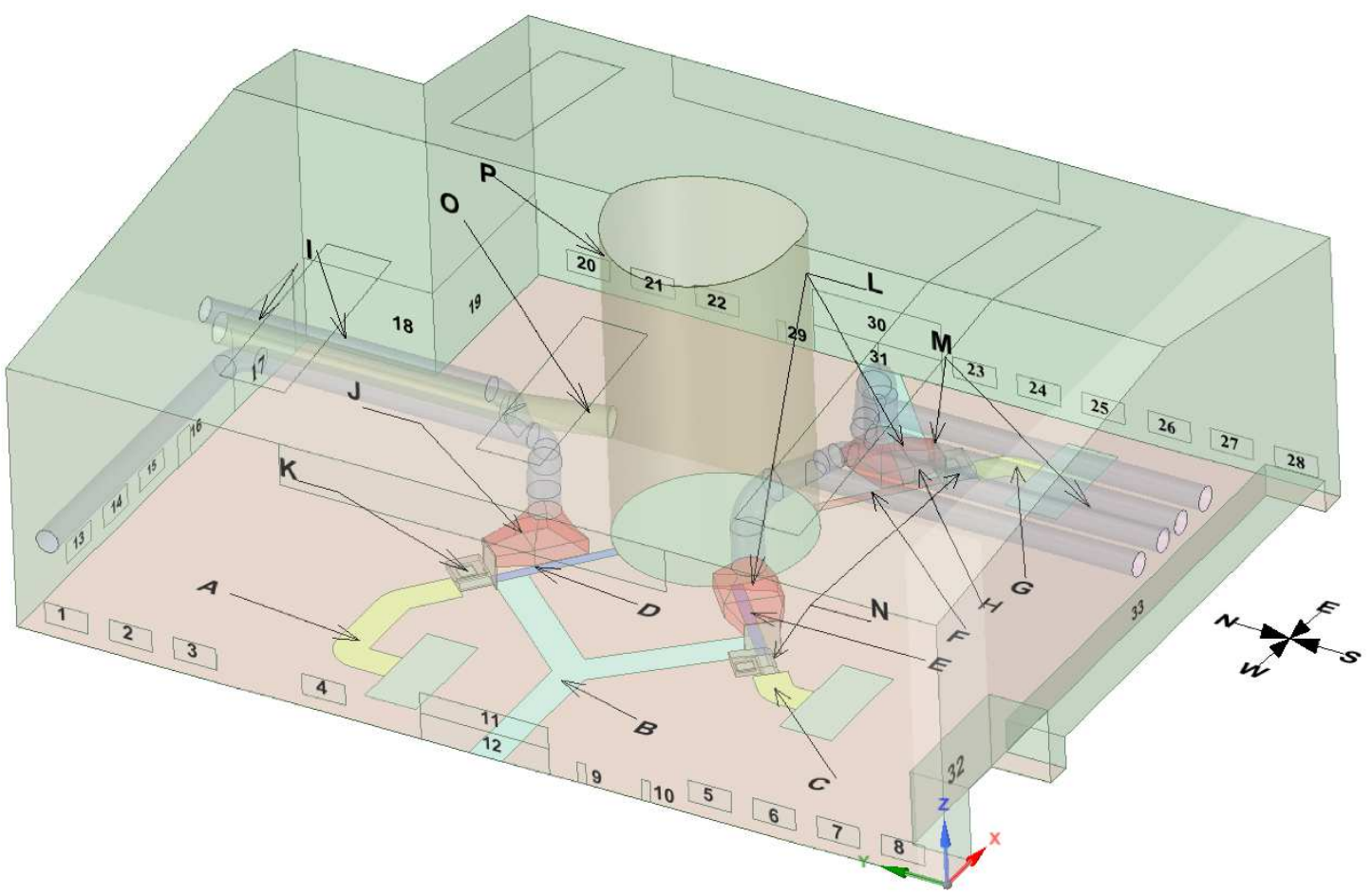

(b) 3D model of the workshop

Fig.1 Layout and main features of the iron workshop

127 Note: 1 8, Westside window; 9 10, Westside small door; 11, Westside Slag ditch door upper 128 side; 12, Westside Slag ditch door; 13 15, Northside window; 16, Northside small door; 17, 129 Northside main entrance; 18 19, Hollow; 20 28, Eastside window; 29, Eastside small door; 13030 , Eastside Slag ditch door upper side; 31, Eastside Slag ditch door; 32 33, Room.

131 A, 2\#Iron trench with cover; B, 2\# and 1\#Slag ditch; C, 1\#Iron trench with cover; D, 2\#Iron 132 ditch; E, 1\#Iron ditch; F, 3\#Iron ditch; G, 3\#Iron trench with cover; H, 3\#Iron ditch; I, 2\# Dust 133 removal pipeline; J, 2\#Iron trench dust hood; K, 2\#Skimmer arched dust hood; L, 1\# and 3\# 134 Iron trench dust hood; M, 1\# and 3\# Dust removal pipeline; N, 1\# and 3\#Skimmer arched dust 135 hood; O, Hot pipeline; P, Blast furnace. 


\subsubsection{Measurement methods}

The Field measurement of this study has two purposes: 1. to provide boundary conditions for numerical simulation, and 2. to analyze the distribution of particle field, temperature field, and flow field within the workshop based on the measurement results, and to determine the reliability of the model method through comparison with the simulation results.

For the measurement of boundary conditions, the researchers used a hand-held portable thermometer and anemometer to measure the air's temperature and wind speed inlet doors and windows. They used an infrared thermometer to measure each wall's temperature and the blast furnace surface, dust hood surface, pipe surface, and other places in the workshop.

148 For the distribution measurement of the particle field, temperature field, and flow 149 field in the workshop, four typical cross-sections are selected as shown in Figure 2.;

150 During the field measurement, the 2\# taphole was tapping, so two cross-sections were selected near the 2\# taphole, which is situated on the iron ditch and the dust hood sections. This is to study the impact of the tapping hole on the plant Influence of internal temperature and particle concentration. The third cross-section is located above the iron plate of the slag ditch on the west side and passes through the center of the blast furnace. Moreover, the fourth cross-section passes through the iron dividing ditch corresponding to the $1 \#$ and $3 \#$ tapholes. These four cross-sections have significant characteristics that symbolized the particle field's distribution, temperature field, and flow field of the 158 entire plant.

159 Considering the difficulty of measurement and the operator's breathing belt's height, 160 the measurement points are located $1.5 \mathrm{~m}$ above the cast iron platform's ground, 161 selecting 7 points for the first, second, and third lines, respectively. Measurement points 162 were unevenly distributed due to items stacked at the workshop's open space and other 163 environmental complexities. During the measurement, the $3 \#$ taphole was under 164 maintenance, so the fourth section only selected four points at the western side. The 165 temperature, wind speed, and particle concentration were measured at each 166 measurement point. Data obtained were used to study the distribution of various

167 physical quantities in the factory building and compare with the simulation results to 168 determine the model's reliability. 


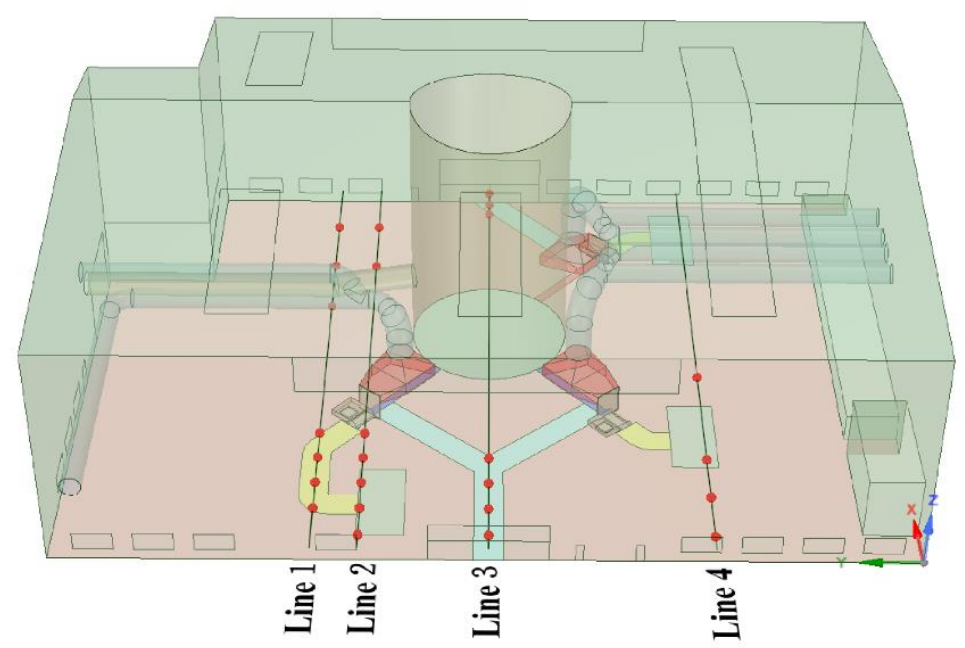

169

170

171

172

173

174

175

176

177

178

179

180

181

182
Fig.2 Schematic diagram of the site measurement location

\subsubsection{Measurement instrument}

Most of the instruments used in field measurement are portable, hand-held instruments. The testo605i wireless temperature and humidity measuring instrument were used the temperature measurement of the air; the testo835-T2 high-temperature infrared thermometer and the testo865 infrared thermal imager were used the temperature measurement of the walls and the surface of the equipment in the workshop. The wind speed is measured using the testo $405 \mathrm{i}$ wireless mini hot-wire anemometer, and the TSI 8534 inhalable particle analyzer is used to determine the particle concentration in the factory. The rangefinder is used to determine the location of the measuring point. The measurement range, accuracy, measurement technology, and specific implementation standards of each instrument are shown in Table 1. 
Table 1 Measuring instrument parameters

\begin{tabular}{|c|c|c|c|c|}
\hline Instrument & Measuring range & Accuracy & $\begin{array}{l}\text { Measuring } \\
\text { technology }\end{array}$ & $\begin{array}{l}\text { Executive } \\
\text { standard }\end{array}$ \\
\hline $\begin{array}{l}\text { testo605iWireless } \\
\text { mini temperature } \\
\text { and humidity } \\
\text { measuring } \\
\text { instrument }\end{array}$ & $\begin{array}{c}\text { The temperature } \\
\text { measurement } \\
\text { range: }-20 \sim+60^{\circ} \mathrm{C} \text {. } \\
\text { The humidity } \\
\text { measurement } \\
\text { range }: 0 \sim 100 \% \\
\text { RH }\end{array}$ & $\begin{array}{c}{\left[ \pm 0.8^{\circ} \mathrm{C}(-20 \sim\right.} \\
\left.0^{\circ} \mathrm{C}\right), \pm 0.5^{\circ} \mathrm{C}(0 \sim \\
\left.\left.+60{ }^{\circ} \mathrm{C}\right)\right] \\
{[5 \sim 80 \% \mathrm{RH}: \pm} \\
(1.8 \% \mathrm{RH}+3 \% \\
\text { Measurements }) \text { at } \\
\left.+25^{\circ} \mathrm{C}\right]\end{array}$ & $\begin{array}{l}\text { NTC (Negative } \\
\text { temperature } \\
\text { coefficient) } \\
\text { Thermistor } \\
\text { capacitive } \\
\text { humidity sensor }\end{array}$ & $\begin{array}{c}\text { ISO } \\
9001: 2008 \\
\text { ISO/IEC } \\
17025: 2005\end{array}$ \\
\hline $\begin{array}{l}\text { testo405iWireless } \\
\text { mini hotline } \\
\text { anemometer }\end{array}$ & $0 \sim 30 \mathrm{~m} / \mathrm{s}$ & $\begin{array}{c} \pm 0.5^{\circ} \mathrm{C} \pm(0.1 \mathrm{~m} / \mathrm{s}+ \\
5 \% \text { Measurements }) \\
(0 \sim 2 \mathrm{~m} / \mathrm{s}) \pm(0.3 \mathrm{~m} / \mathrm{s} \\
+5 \% \\
\text { Measurements }) \\
(2 \sim 15 \mathrm{~m} / \mathrm{s})\end{array}$ & $\begin{array}{l}\text { NTC Negative } \\
\text { temperature } \\
\text { coefficient) } \\
\text { thermistor hot } \\
\text { wire }\end{array}$ & $\begin{array}{c}\text { ISO } \\
9001: 2008 \\
\text { ISO/IEC } \\
17025: 2005\end{array}$ \\
\hline $\begin{array}{l}\text { testo835-T2 High } \\
\text { temperature } \\
\text { infrared } \\
\text { thermometer }\end{array}$ & $-10^{\circ} \mathrm{C} \sim+1500^{\circ} \mathrm{C}$ & $\begin{array}{l} \pm 2.0^{\circ} \mathrm{C} \text { or } \pm 1 \% \\
\text { Measurements }\end{array}$ & $\begin{array}{c}\text { TypeK }(\mathrm{NiCr}-\mathrm{Ni}) \\
\text { Infrared } \\
\text { temperature } \\
\text { measurement }\end{array}$ & $\begin{array}{c}\text { ISO } \\
\text { 9001:2008 } \\
\text { ISO/IEC } \\
\text { 17025:2005 }\end{array}$ \\
\hline $\begin{array}{l}\text { testo865 Thermal } \\
\text { imaging camera }\end{array}$ & $-20 \sim+280^{\circ} \mathrm{C}$ & $\begin{array}{l}\text { Thermal sensitivity } \\
\quad<0.12^{\circ} \mathrm{C}\end{array}$ & $\begin{array}{l}\text { Infrared image } \\
\text { output }\end{array}$ & $\begin{array}{c}\text { EMC:2014/30/ } \\
\text { EU }\end{array}$ \\
\hline $\begin{array}{c}\text { TSI8534 } \\
\text { Inhalable } \\
\text { particulate matter } \\
\text { analyzer }\end{array}$ & $0.001 \sim 150 \mathrm{mg} / \mathrm{m}^{3}$ & $\pm 5 \%$ & $\begin{array}{l}\text { Light scattering } \\
\text { laser photometer } \\
\text { and optical } \\
\text { particle counter } \\
\text { (OPC) }\end{array}$ & ISO 12103-A1 \\
\hline $\begin{array}{c}\text { UNI-T Unitech } \\
\text { 120m rangefinder }\end{array}$ & $0 \sim 120 \mathrm{~m}$ & $\pm 2 \mathrm{~mm}$ & Laser Ranging & $\begin{array}{c}\text { GB/T } 14267- \\
2009 \\
\end{array}$ \\
\hline
\end{tabular}

184

185

\section{CFD model}

\section{$186 \quad 3.1$ Flow model}

187 In engineering, the Reynolds time-average equation after time-averaging the control

188 equation is often used to study the airflow, and the turbulence model is introduced to

189 deal with the turbulent motion of the airflow (Wang et al,2015).

$$
\frac{\partial(\rho \emptyset)}{\partial t}=\operatorname{div}(\rho \emptyset \vec{u})=\operatorname{div}(\Gamma \operatorname{grad} \emptyset)+S
$$

191 Where $\varnothing$ is a general variable, which can represent solution variables such as $u, v$, $192 \mathrm{w}, \mathrm{T} ; \Gamma$ is the generalized diffusion coefficient; $\mathrm{S}$ is the generalized source phase.

193 The two-equation model is widely used in engineering, including the standard $\mathrm{k}-\varepsilon$ 194 model, RNG k- $\varepsilon$ model, and Realizable k- $\varepsilon$ model. Among them, the Realizable k- $\varepsilon$ 
model can better simulate rotating uniform shear flow; unbounded shear flow, including mixed layer, plane, and circular jet; channel flow and flat plate boundary layer with and without pressure gradient; separation Flow is a significant improvement of the standard $\mathrm{k}-\varepsilon$ model (Shih et al, 1995). The realizable k- $\varepsilon$ model consumes computer resources between the two types. Liu YL (2015) comparatively studied three models, showing that the Realizable $\mathrm{k}-\varepsilon$ model has the best simulation results in tall industrial plants under the action of heat pressure. Also, Huang et al. (2019) demonstrated that the Realizable $\mathrm{k}-\varepsilon$ turbulence model is suitable for high-temperature buoyant jets. After analysis, the paper adopted the Realizable k- $\varepsilon$ model to reflect better the flow state of the blast furnace's flow field. Due to the extensive temperature range designed in this paper, the airflow is subject to the buoyancy caused by the large density difference, necessitating selecting the Full Buoyancy Effects option.

Moreover, since high-temperature objects are up to $1200^{\circ} \mathrm{C}$ in the simulated plant, there is a large temperature difference, so the density is mainly a temperature function. Therefore, an incompressible ideal gas density processing method is used (Zhou et al,2019). Considering the influence of radiation on the industrial thermal environment (Wang et al,2014), the DO radiation model is adopted.

This paper also adopts the SIMPLE algorithm based on pressure, considering the energy equation and gravity. The direction of gravity is the $\mathrm{Z}$ axis's Positive direction, and the acceleration of gravity is $-9.81 \mathrm{~m} / \mathrm{s}^{2}$. Thus adopting the body force weighted pressure interpolation format, which is mainly suitable for volume force flow. For the accuracy of calculation, the momentum equation, energy equation adopt the secondorder upwind discrete format.

\subsection{Particle dynamic model}

Liu et al. (2006) found that the iron casting yard's indoor air particulate matter accounts for $91.4 \%$ of PM10, and PM2.5 accounts for 25.5\%. Similarly, Liu et al. (2015) found that the main component of PM10 discharged into the atmosphere during ironmaking is PM2.5. Therefore, this article focuses on the particulate matter with a diameter of 2.5 microns.

The dust-bearing airflow in the iron casting yard is composed of high-temperature gas and soot particles, which are gas-solid two-phase flow. The gas-solid two-phase flow simulation is generally divided into Eulerian-Eulerian and Eulerian-Lagrangian methods. Euler method treats the particle phase as a continuous phase to solve the particle conservation equation. Lagrangian method regards the air phase as a continuous phase to solve the time-averaged N-S equation and the particle phase as a discrete phase and obtains the motion orbit of a single particle by solving the momentum equation of the particle (Zhao et al. 2008). For the high-temperature dust-containing airflow with the volume fraction of particulate matter less than $10 \%$ in this paper, the Lagrangian method is generally used. Therefore, the DPM model is used for the simulation of the solid phase. The fluid is regarded as a continuous phase, and the discrete phase is solved 
by tracking a large number of particles in the flow field. This paper uses the random trajectory model and the unidirectional coupling discrete phase model to simulate the particle phase turbulent diffusion flow. Likewise, the Lagrangian method is used to track the particle trajectory; the dynamic particle equation is generally given as:

$$
m \frac{d_{v}}{d_{t}}=F_{d}+F_{g}+F_{T}+F_{b}+F_{\text {saffman }}+F_{p}+F_{R}
$$

Where $m$ is the mass of the particle, $v$ is the velocity of the particle, $t$ is the time, $F_{d}$ is the fluid drag force received by the particle, $\mathrm{F}_{\mathrm{g}}$ is the gravity received by the particle, $\mathrm{F}_{\mathrm{T}}$ is the thermophoretic force received by the particle, $\mathrm{F}_{\mathrm{b}}$ is the Brown force received by the particle, and $F_{\text {saffman }}$ is the Saffman lift force on the particle, $F_{p}$ is the pressure gradient force on the particle, and $F_{R}$ is the heat radiation force on the particle.

When the volume fraction of particles in the dust-containing airflow is less than $10 \%$, particles' interaction can be ignored. Because the high-temperature airflow has a large temperature gradient, the thermophoretic force caused by the temperature gradient needs to be considered, and the Brownian force and Saffman lift due to the velocity gradient in the flow field.

In his article, Liu Yi (2016) mentioned the particles' composition in the blast furnace casting yard, as shown in Table 2.

Table 2 Smoke composition

\begin{tabular}{ccccccccc}
\hline Ingredient & $\mathrm{Fe}_{2} \mathrm{O}_{3}$ & $\mathrm{TFe}$ & $\mathrm{CaO}$ & $\mathrm{MgO}$ & $\mathrm{SO}_{2}$ & $\mathrm{P}$ & Burn ashes & $\mathrm{FeO}$ \\
\hline $\begin{array}{c}\text { Proportion } \\
(\%)\end{array}$ & 59.76 & 48.9 & 5.38 & 0.3 & 5.06 & 0.013 & 13.84 & 9.12 \\
\hline
\end{tabular}

It can be seen from the table that the main component of the particulate matter discharged from the iron field is $\mathrm{Fe}_{2} \mathrm{O}_{3}$, so the particulate matter parameter is taken as the iron oxide parameter, the density is $4580 \mathrm{~kg} / \mathrm{m}^{3}$, the thermal conductivity is $0.55 \mathrm{w} / \mathrm{m} \cdot \mathrm{K}$, and the specific heat capacity is $710 \mathrm{~J} / \mathrm{kg} \cdot \mathrm{K}$.

\subsection{Boundary conditions}

According to the iron casting yard characteristics, the airflow generally enters from the lower door window and flows freely from the side windows and roof skylights. The air inlet adopts the speed inlet's boundary condition; its temperature is the outdoor measured ambient temperature, and its speed is the speed measured on-site. The speed boundary conditions are defined in Tables 3 and 4 . The boundary conditions for the plant's fixed wall are the first type of boundary conditions, and the specific parameter values are shown in Table 5.

During regular tapping, the most smoke and dust are released from the tap hole, and a large amount of soot is also emitted from the slag ditch cover on the spot, so the two smoke and dust emission points selected at the slag ditch cover are set as the dust- 
producing area as shown in Figure 3. According to the literature (Liu Yi, 2016), the main ditch's dust output is about $39.1 \mathrm{~kg} / \mathrm{h}$, the initial speed of smoke and dust is 0 $2.3 \mathrm{~m} / \mathrm{s}$, and the slag's dust output ditch is about $3.1 \mathrm{~kg} / \mathrm{h}$. The speed tested in the field is

272 about $0.8 \mathrm{~m} / \mathrm{s}$, and the content of PM2.5 is about $20 \%$. These particle mass flow and speed settings are shown in Table 6 .

Fig.3 Dust production point layout

Table 3 Skylight boundary condition

\begin{tabular}{ccc}
\hline & Boundary conditions & DMP-Injection \\
\hline $\begin{array}{c}\text { Roof windows and side } \\
\text { windows }\end{array}$ & Outflow & Escape \\
\hline
\end{tabular}

Producing dust source 1

$14500 \mathrm{~mm}$

$7500 \mathrm{~mm}$

Producing dust source 3

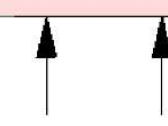

roducing dust source 2

$1000 \mathrm{~mm}$

3 
Table 4 Door and window boundary conditions

\begin{tabular}{|c|c|c|c|c|c|}
\hline & $\begin{array}{l}\text { Position } \\
\text { number }\end{array}$ & $\begin{array}{l}\text { Boundary } \\
\text { conditions }\end{array}$ & $\begin{array}{c}\text { Velocity } \\
\text { magnitude(m/s) }\end{array}$ & $\begin{array}{c}\text { Temperature } \\
\left({ }^{\circ} \mathrm{C}\right)\end{array}$ & $\begin{array}{c}\text { DMP- } \\
\text { Injection }\end{array}$ \\
\hline \multirow{9}{*}{ East } & 23 & \multirow{9}{*}{ Velocity-inlet } & 1.20 & \multirow{9}{*}{29} & \multirow{9}{*}{ Escape } \\
\hline & 24 & & 1.20 & & \\
\hline & 25 & & 1.20 & & \\
\hline & 26 & & 1.30 & & \\
\hline & 27 & & 1.00 & & \\
\hline & 28 & & 0.90 & & \\
\hline & 29 & & 1.50 & & \\
\hline & 30 & & 0.90 & & \\
\hline & 31 & & 0.90 & & \\
\hline \multirow{11}{*}{ West } & 1 & \multirow{11}{*}{ Velocity-inlet } & 0.15 & \multirow{11}{*}{30} & \multirow{11}{*}{ Escape } \\
\hline & 2 & & 0.12 & & \\
\hline & 3 & & 0.12 & & \\
\hline & 4 & & 0.25 & & \\
\hline & 5 & & 0.10 & & \\
\hline & 6 & & 0.15 & & \\
\hline & 7 & & 0.20 & & \\
\hline & 8 & & 0.20 & & \\
\hline & 9 & & 0.40 & & \\
\hline & 10 & & 0.30 & & \\
\hline & 11 & & 0.60 & & \\
\hline \multirow{5}{*}{ North } & 13 & \multirow{5}{*}{ Velocity-inlet } & 0.80 & \multirow{5}{*}{29} & \multirow{5}{*}{ Escape } \\
\hline & 14 & & 1.00 & & \\
\hline & 15 & & 1.20 & & \\
\hline & 16 & & 0.80 & & \\
\hline & 17 & & 1.00 & & \\
\hline
\end{tabular}

Table 5 Wall and pipe boundary conditions

\begin{tabular}{cccc}
\hline Position number & $\begin{array}{c}\text { Boundary } \\
\text { conditions }\end{array}$ & $\begin{array}{c}\text { Temperature } \\
{ }^{\circ} \mathbf{C}\end{array}$ & DMP-Injection \\
\hline East wall & & & \\
West wall & & 35 & \\
North wall & & & \\
East wall & & 34 & \\
Floor & & 31 & Trap \\
32-33 & 40 & \\
P & & 80 & \\
O & & 40 & \\
I,M & & 1100 & \\
D & 750 & \\
E,H & & 110 & \\
A,C,H & & 55 & \\
K,N $N$ & 200 & \\
B,H & & & \\
\hline
\end{tabular}


Table 6 The mass flux and initial velocity of the particulate matter

\begin{tabular}{ccc}
\hline Position & Particle mass flow & Initial velocity \\
\hline Producing dust source1 & $0.002 \mathrm{~kg} / \mathrm{s}$ & $2 \mathrm{~m} / \mathrm{s}$ \\
Producing dust source2 & $1.5 \mathrm{e}-4 \mathrm{~kg} / \mathrm{s}$ & $0.8 \mathrm{~m} / \mathrm{s}$ \\
Producing dust source3 & $1 \mathrm{e}-5 \mathrm{~kg} / \mathrm{s}$ & $0.8 \mathrm{~m} / \mathrm{s}$ \\
\hline
\end{tabular}

\section{Results}

\subsection{Measurement results}

To provide boundary conditions for the numerical simulation, the speed of the factory building's windows, the temperature of the external walls, and the walls of the internal facilities were measured with an anemometer and a thermometer. The specific measured values are shown in Tables 3, 4, and 5. To verify the CFD model, an anemometer, a thermometer, and a particle analyzer were used to determine the particle concentration, wind speed, and temperature on the four characteristic lines of the $1.5 \mathrm{~m}$ plane in the blast furnace casting yard. The details are shown in Figures 4, 5, and 6.

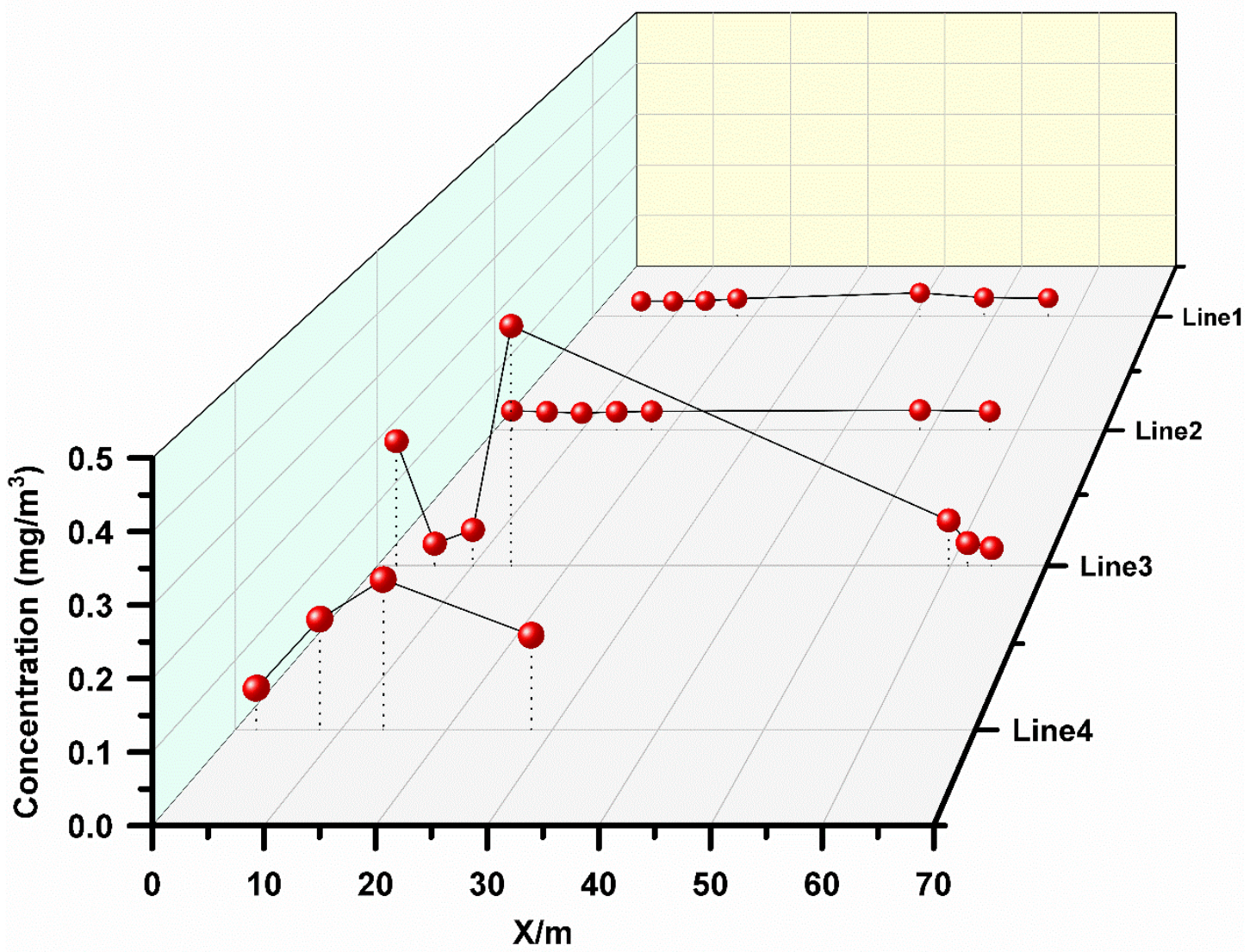

Fig.4 Distribution of PM2.5 concentration 


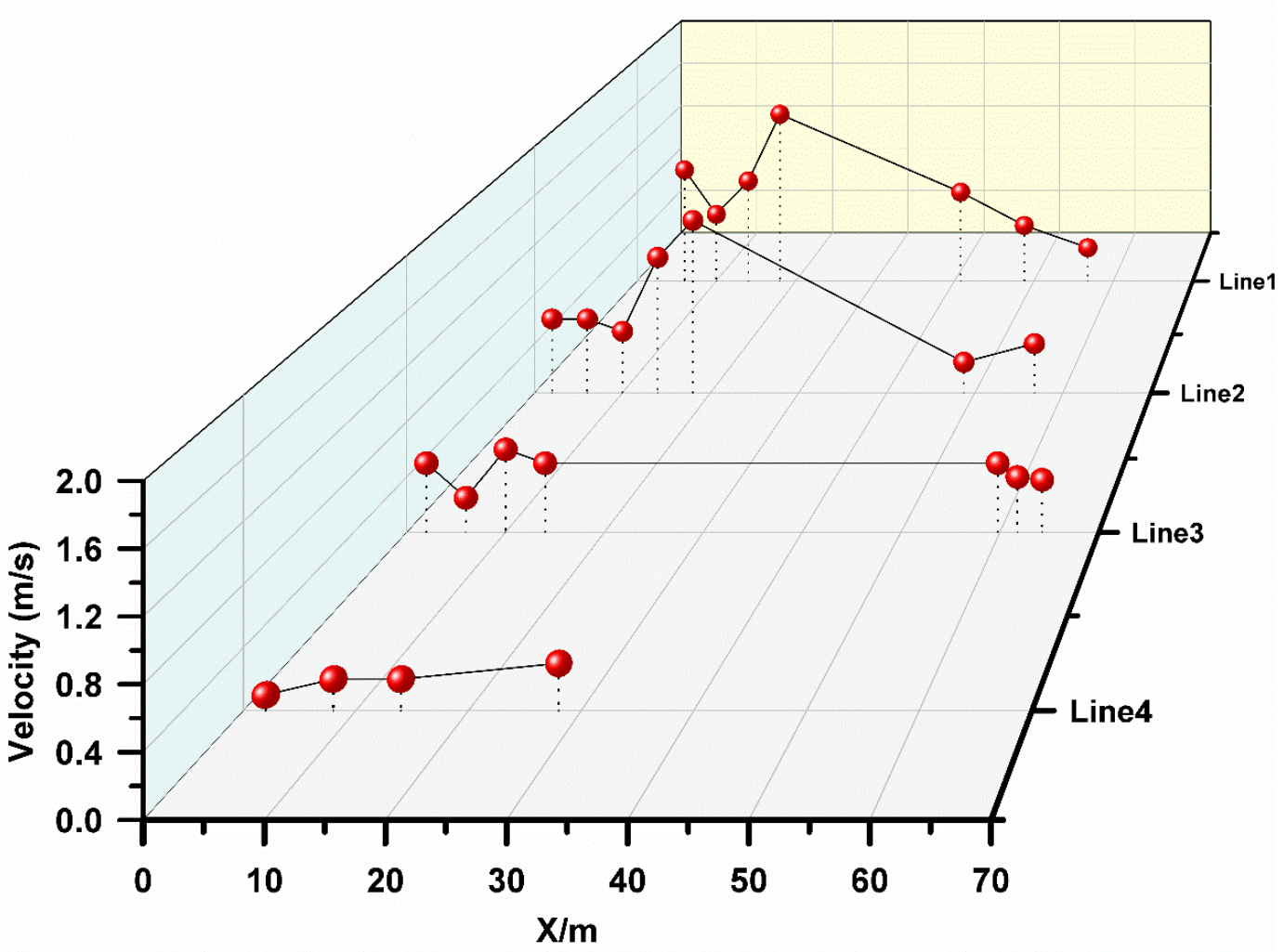

297

Fig.5 The velocity distribution

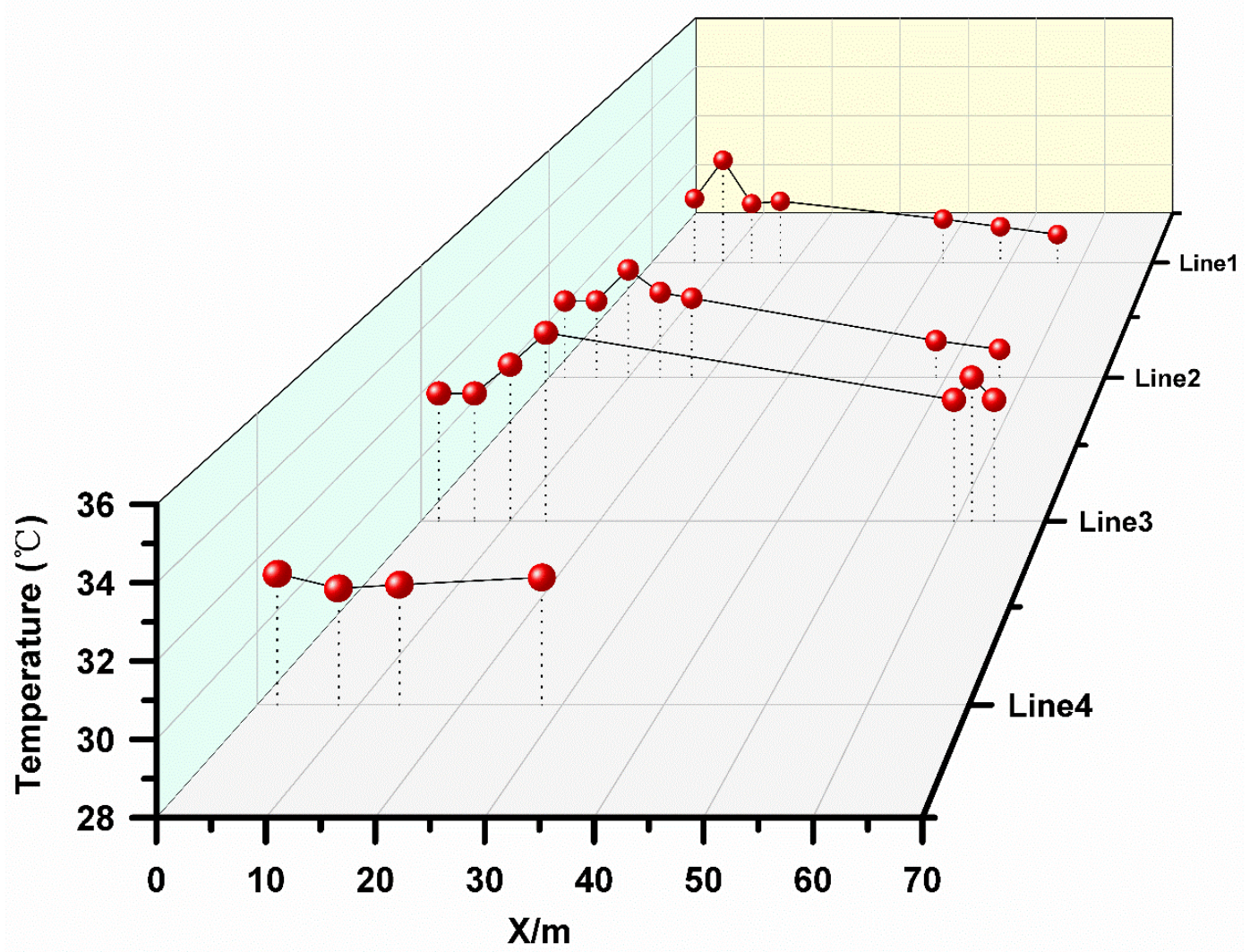

Fig.6 The temperature distribution 


\subsubsection{Grid independence verification}

The grid's quantity and quality are the key factors affecting the numerical simulation of the factory building. Because there are many irregular geometric figures inside the factory building, the overall shape is relatively complicated, and it is not easy to generate hexahedral meshes, so tetrahedral meshes are used for division in the calculation. Therefore, the paper uses the Tetrahedrons method to generate a full tetrahedron mesh. Because the plant has a cylindrical surface such as a blast furnace and pipes, it adopts Curvature's distribution method. The grids of heat source, air inlet, and air outlet are densely divided, and the grid inside the plant is relatively sparse. The accuracy of the two-phase flow simulation for the grid is also very high, so the grid divided in the calculation area must be sufficiently fine. A coarse grid will cause errors in the tracking of particles. Moreover, too much grid will require higher computer performance and a waste of valuable resources. To address this issue, the paper divided the calculation area into three different numbers of grids and compared the numerical simulation results under different numbers of grids to determine a grid that meets the calculation requirements and has high accuracy level faster calculation speed. The three different grids are as follows: 4.6 million, 9.89 million, and 11.4 million.

319 Comparing the measured speed on the fourth line, as shown in Figure 7, it can be seen from the figure that from 4.6 million to 11.4 million, the speed change trend corresponding to the 4.6 million grid is relatively large. However, the speed change trends corresponding to 9.89 million and 11.4 million grids are similar. It proves that the grid number's accuracy is 9.89 million, and the accuracy is high enough. At this time, increasing the number of grids does not make much sense, as it will slow down the calculation speed. In this paper, the grid division uses a grid growth rate of 1.2, the global size is $301 \mathrm{~mm}$, and the heat source surface and the inlet and outlet are $250 \mathrm{~mm}$, and the number of generated grids is 9.89 million for numerical simulation calculation. 


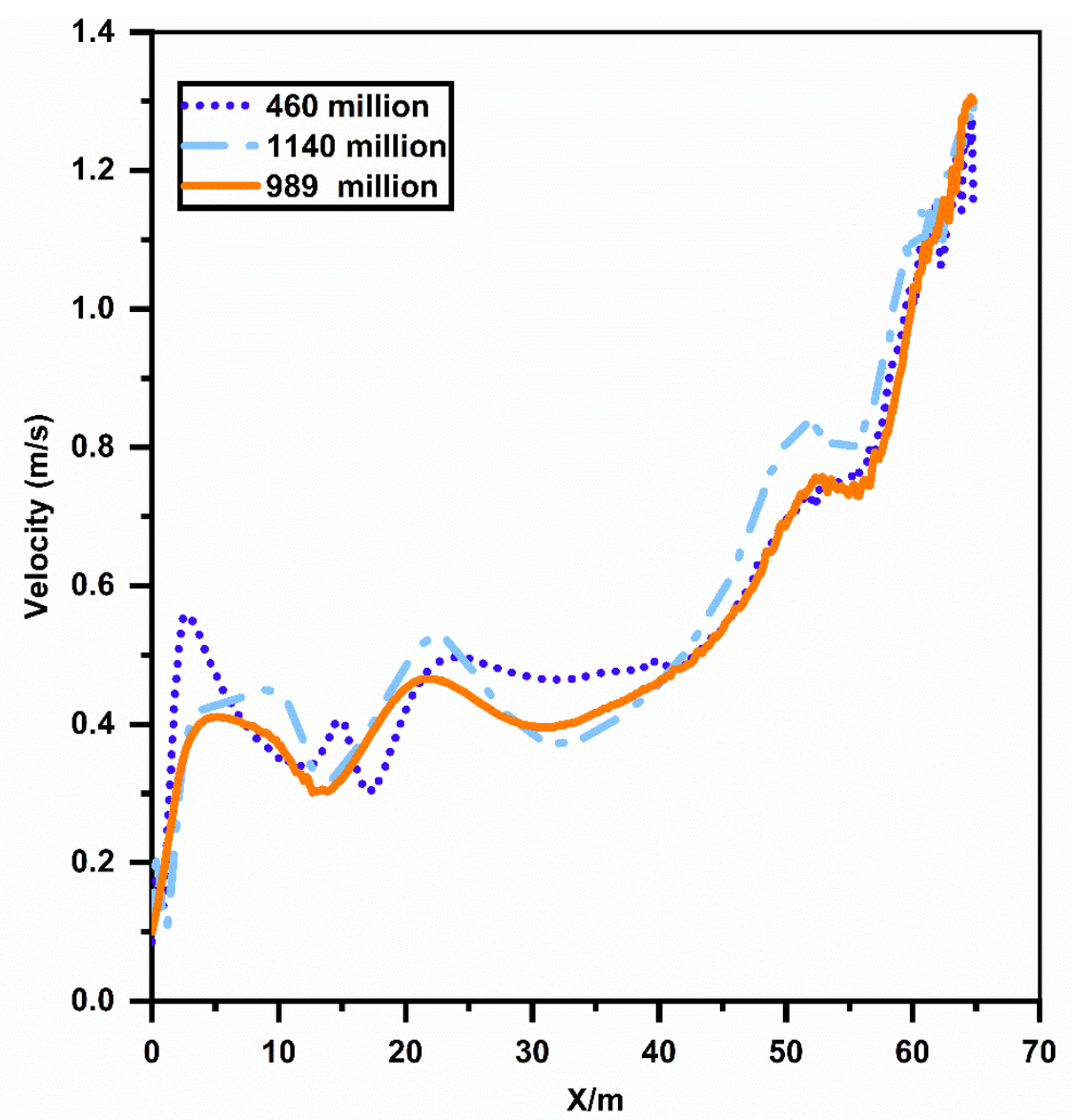

Fig.7 Grid independence verification

\subsubsection{Numerical simulation verification}

The measurement points of air temperature, velocity, and particle concentration are as described in section 2.2. The numerical simulation results are compared with the experimental results shown in Figures 8, 9, and 10. Analysis of the first line shows fewer obstructed objects, and the distance from the doors and windows is relatively closed. So the measured temperature and concentration are relatively uniform, and the speed in the middle of the suction effect of the dust hood is tremendous. The second line of the measurement is located under the dust hood at about 25 meters, so the temperature, speed, and concentration are higher. Due to the complicated nature of the plant, the comparison result of the third line is inconsistent. Further, the model simplified the support around the blast furnace, mud bombardment, and other objects and observed no obstruction behind the slag ditch; the airflow quickly enters the back of the blast furnace leads to a higher speed, lower concentration, and lower temperature. For the fourth line in the factory building's depth, the particulate matter accumulates due to the longitudinal airflow interference, leading to a relatively high concentration. From the above comparison, it can be considered that the numerical model and calculation method in this paper have a reasonable degree of reliability and acceptability. 

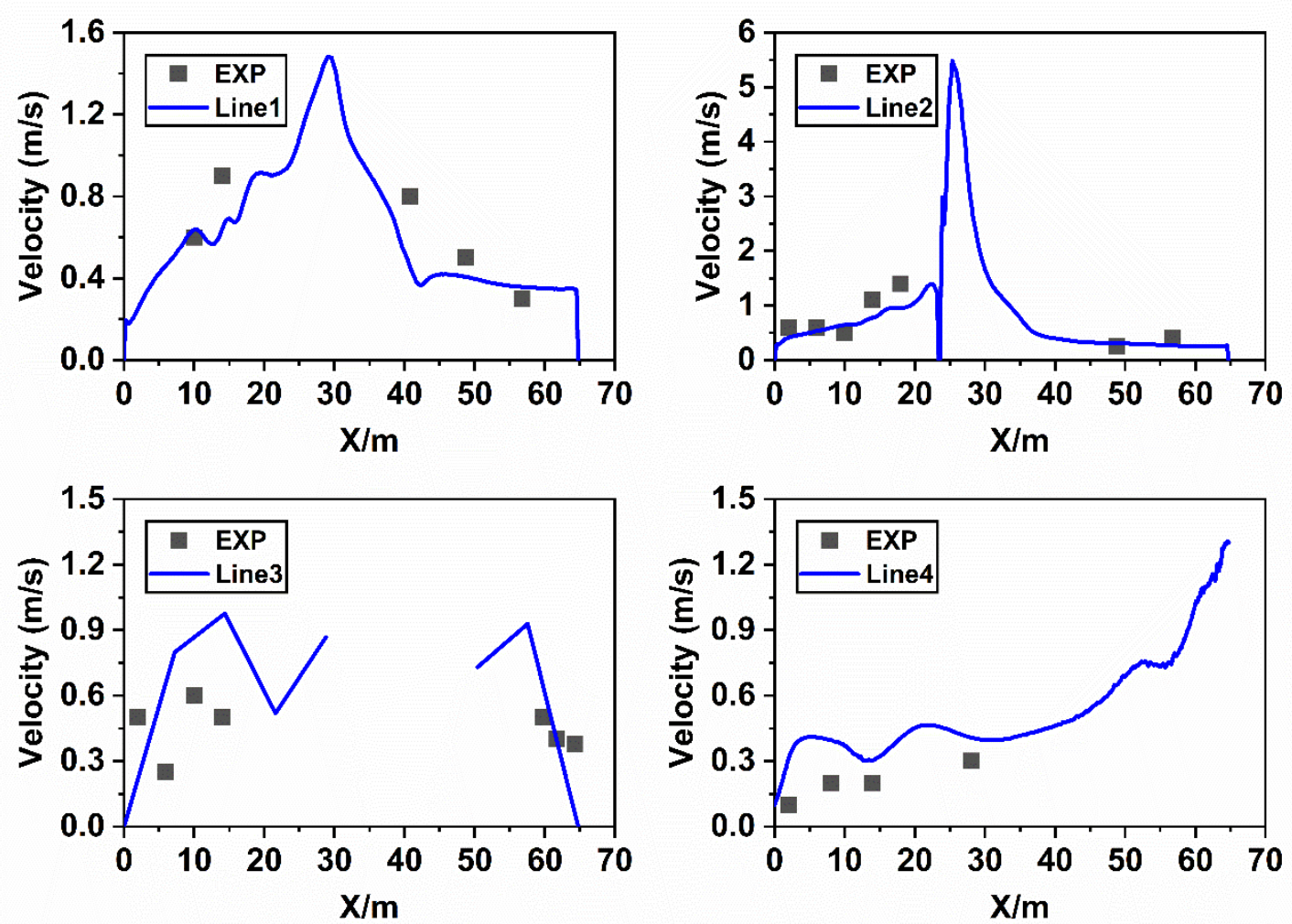

Fig.8 Comparison of the simulated air velocity with the experimental data on Line1 to 349 Line4
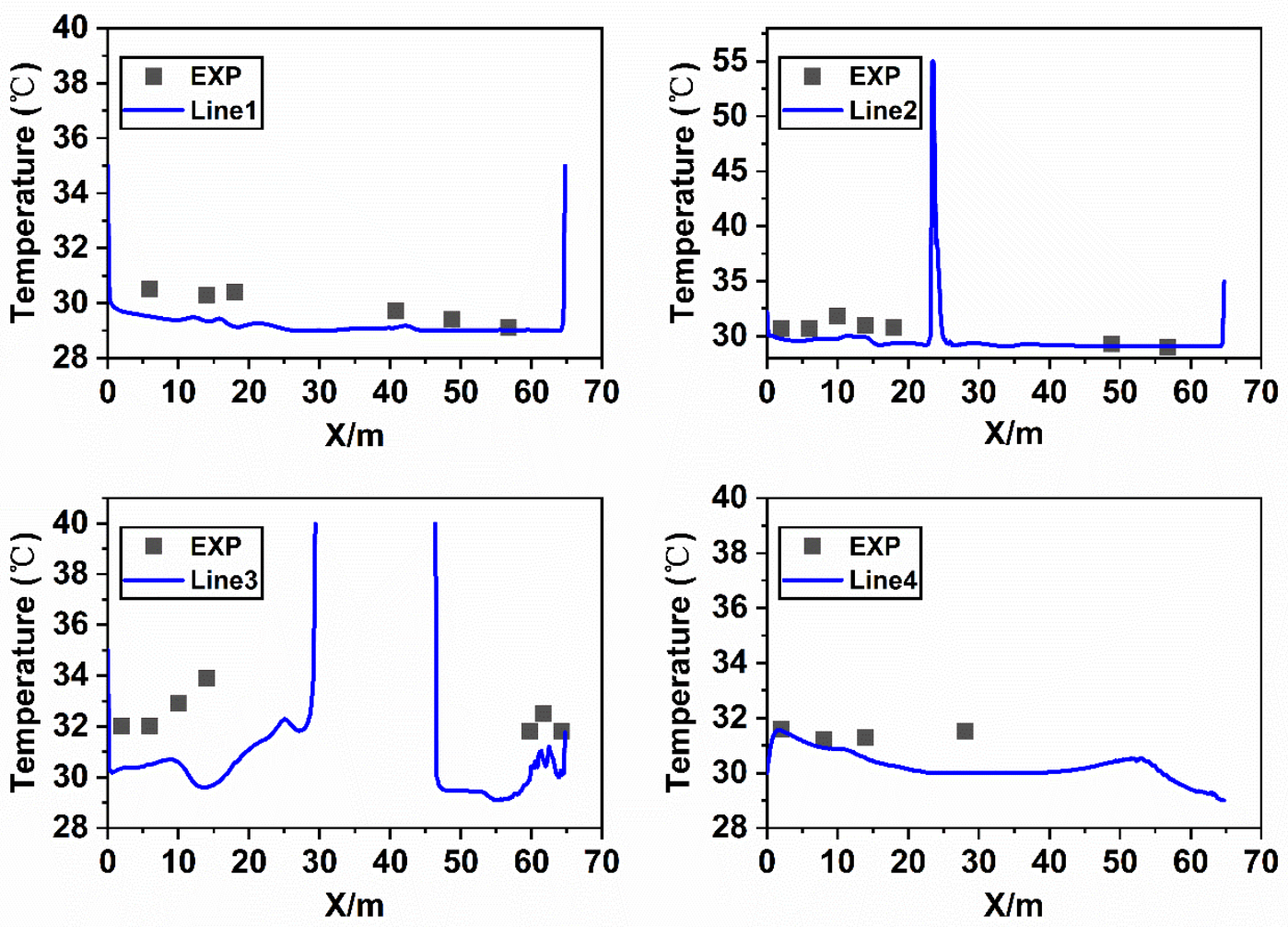

Fig.9 Comparison of the simulated air temperature with the experimental data on Line 1 to Line4 

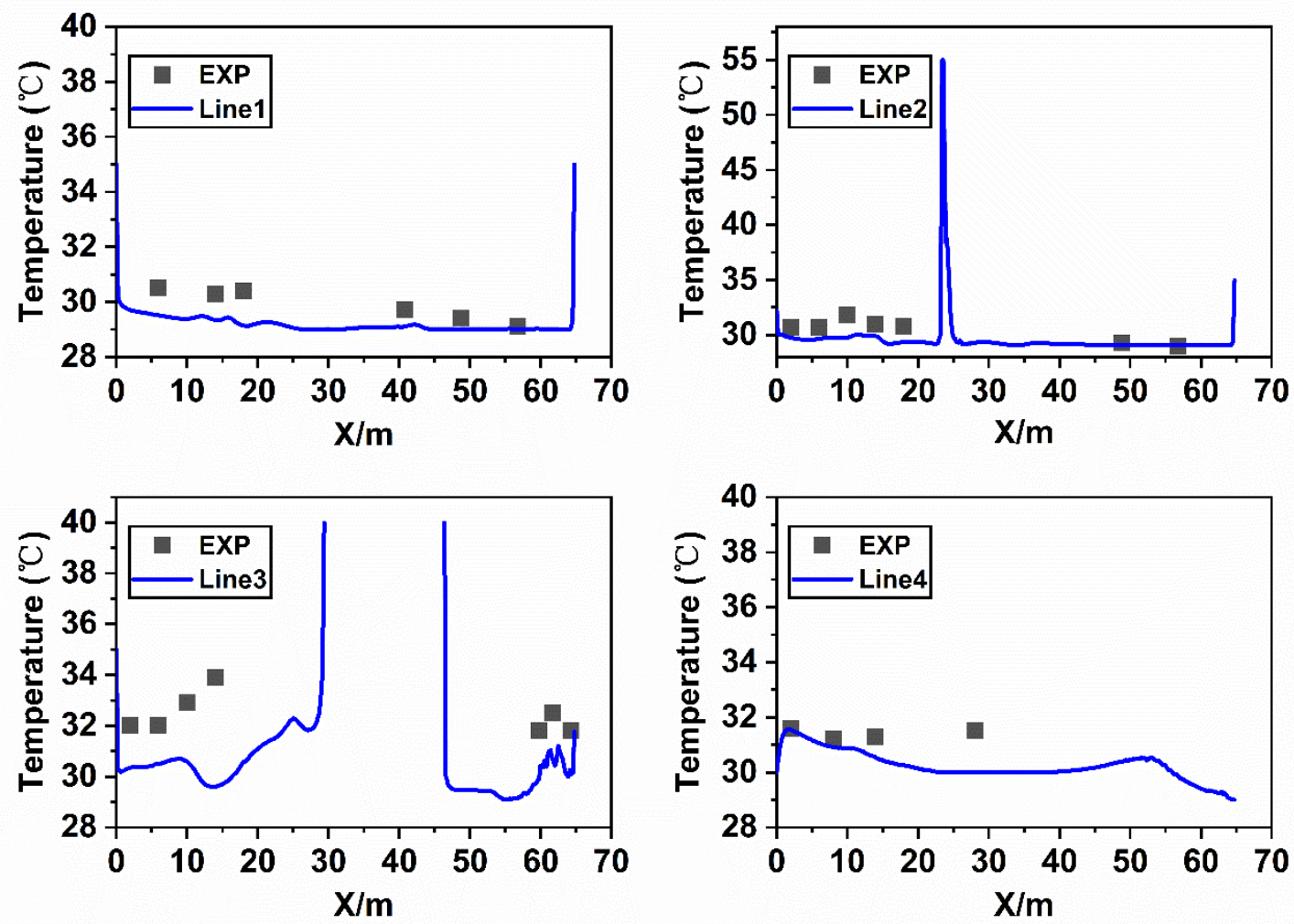

Fig.10 Comparison of the simulated PM2.5 concentration with the experimental data on Line 1 to Line4

\subsection{Performances of the ventilation system}

Since the $\mathrm{z}=1.5 \mathrm{~m}$ plane is precisely where most people breathe, the flow field, temperature field, and concentration field can best reflect human feelings. Figure 11 shows the temperature distribution on this plane. It can be observed from the figure that the temperature in most areas is below $31^{\circ} \mathrm{C}$. Due to the sweep of the longitudinal airflow, the plume caused by the heat source affects the rear right of the casting yard, and so, the high-temperature area appears on the right of the slag ditch (about $33^{\circ} \mathrm{C}$ ); most of the rear temperature is below $31^{\circ} \mathrm{C}$, which is suitable for workers to operate. The surrounding area above the main operational ditch is as high as $40^{\circ} \mathrm{C}$, and the temperature of the non-working main ditch also reaches $750^{\circ} \mathrm{C}$, so the surrounding temperature above it is also as high as about $35^{\circ} \mathrm{C}$. 

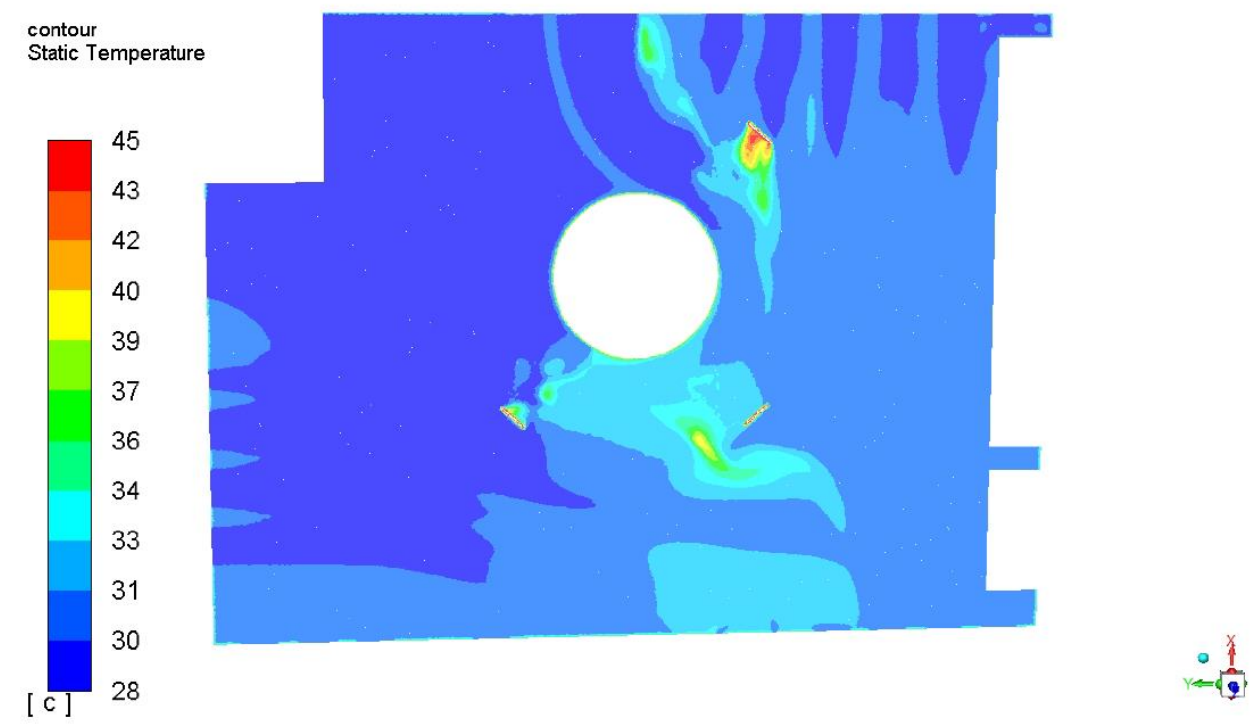

Fig.11 The temperature cloud map of the $\mathrm{z}=1.5 \mathrm{~m}$ plane

The human body's health, self-feeling, and working ability depend on the comfort of the room. In industrial buildings, the human body's thermal comfort directly affects workers' labor efficiency and health. PMV is a recognized thermal environment evaluation index, however the PMV calculation model contains many variables and the calculation is very complicated, this paper adopts simplified algorithm(Ou et al, 2018). According to equations (3) to (6), the cloud map (12) is obtained, and it can be observed that the PMV in the active area of the human body is mostly around 3. Therefore, the thermal comfort of workers is relatively low.

$$
\begin{gathered}
(M-W)-\frac{P M V}{K_{M}}=3.05\left[5.733-0.007(M-W)-P_{a}\right]+0.42(M-W-58.15) \\
+1.73 \times 10^{-2} M\left(5.867-P_{a}\right)+1.4 \times 10^{-3} M\left(34-t_{a}\right)+h_{c r} f_{c l}\left(t_{s k}-t_{o}\right) F_{c l} \\
h_{c r}=h c+0.69 h_{r} \\
t_{o}=\frac{0.69 h_{r} t_{r}+h c t_{a}}{0.69 h_{r}+h c} \\
F_{c l}=\frac{1}{1+0.155 h_{c r} f_{c l} I_{c l}}
\end{gathered}
$$

Where $\mathrm{M}$ is the human energy metabolism rate, $\mathrm{W} / \mathrm{m}^{2} ; \mathrm{W}$ is the mechanical work done by the human body, $\mathrm{W} / \mathrm{m}^{2}$; $\mathrm{Pa}$ is the partial pressure of water vapor around the human body, $\mathrm{KPa} ; \mathrm{t}_{\mathrm{a}}$ is the ambient temperature of the human body, ${ }^{\circ} \mathrm{C} ; \mathrm{h}_{\mathrm{cr}}$ is the comprehensive sensible heat transfer Thermal coefficient; $h_{c}$ is the convective heat transfer coefficient, $\left(\mathrm{W} / \mathrm{m}^{2} \cdot{ }^{\circ} \mathrm{C}\right) ; \mathrm{h}_{\mathrm{r}}$ is the linear radiation heat transfer coefficient, $\left(\mathrm{W} / \mathrm{m}^{2} \cdot \mathrm{K}\right)$; to is the converted temperature, ${ }^{\circ} \mathrm{C}$; $\mathrm{tr}$ is the average environmental radiation temperature; tsk is the average human skin temperature, ${ }^{\circ} \mathrm{C}, \mathrm{F}_{\mathrm{cl}}$ is the basic heat transfer efficiency of clothing; $\mathrm{f}_{\mathrm{cl}}$ is the area coefficient of clothing; and $\mathrm{I}_{\mathrm{cl}}$ is the effective thermal resistance of clothing. 


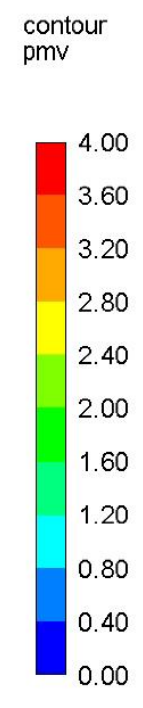

391

392

393

394

395

396

397

398

399

400

401

402

403

404

405

406

407

408

409
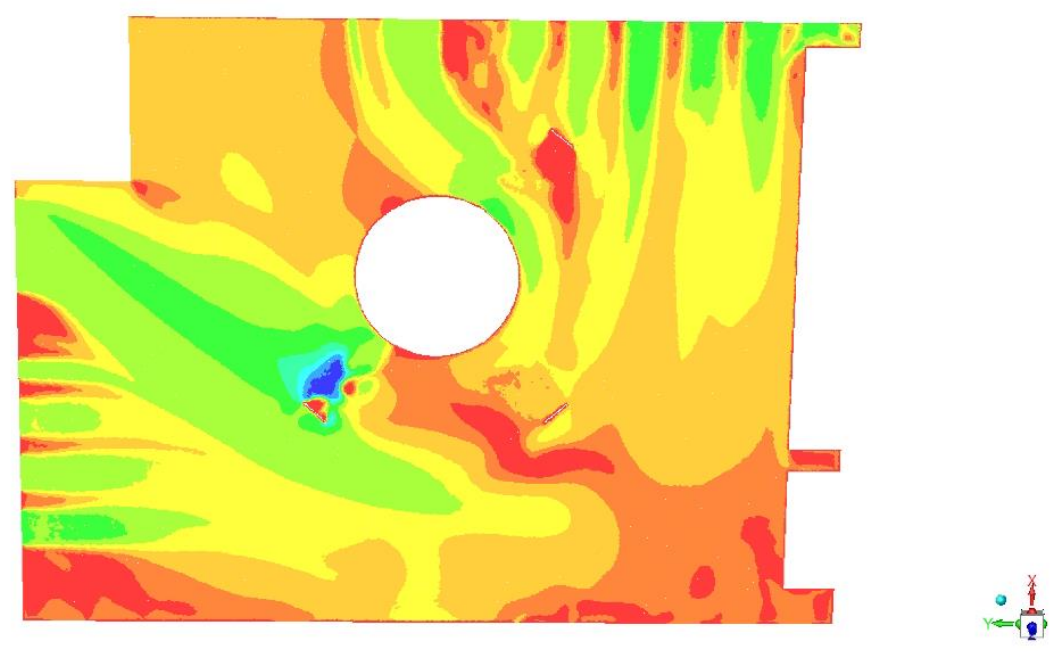

Fig.12 PMV value of the $\mathrm{z}=1.5 \mathrm{~m}$ plane

As shown in Figure 13, the plant's largest concentration point is the area where the main ditch of the blast furnace is connected. Also, a high concentration area appears on the slag ditch's right side; this is due to the main ditch's high-temperature zone and the suction effect of the dust hood above it. There is an apparent high-speed zone at the left front of the main ditch, making it is easier for the airflow to bypass the left side of the blast furnace and reach the rear of the casting yard. However, as the pressure in the factory building's depths increases, the speed starts to decrease, leading to a larger concentration of particulate matter behind the blast furnace. According to CRAES (2012), the indoor PM2.5 concentration limit is $75 \mu \mathrm{g} / \mathrm{m}^{3}$, and the concentration of the entire respiratory area is basically below $80 \mu \mathrm{g} / \mathrm{m}^{3}$, which is considered as mild pollution.

Analysis of Figures 11 and 13 shows the influence of obstacles in the factory building on airflow (Zou et al. 2005). When the air flows through obstacles, it circumvents and generates vortex areas, leading to a gradual reduction in airflow speed, which causes the air distribution in the ventilated space to be very uneven. Hence, the more the airflow goes deep inside the workshop, the harder it is to drive the airflow, making it difficult for air to circulate smoothly and drain from the skylight, leading to particulate matter accumulation and rising temperature. 

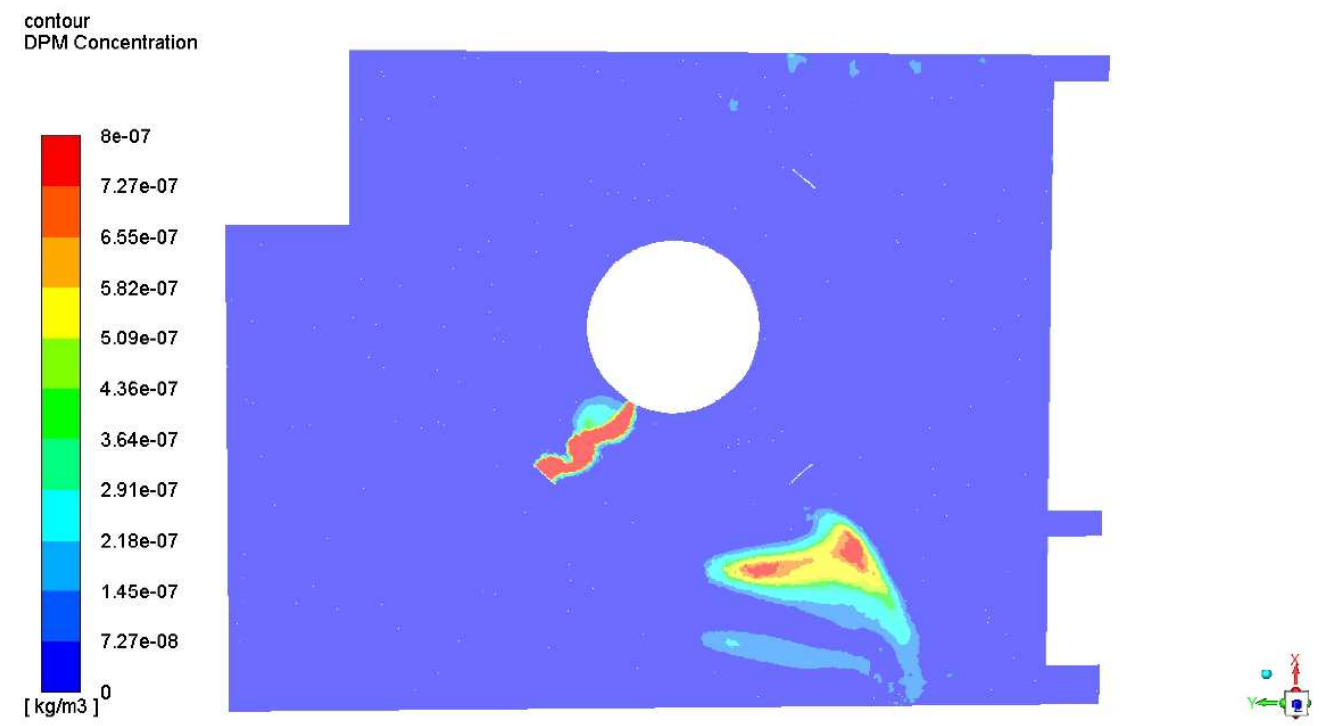

Fig.13 The PM2.5 concentration cloud map of the $z=1.5 \mathrm{~m}$ plane

Figures 14 and 15 reflect specific characteristics of the iron yard's temperature and particle concentration in height direction. From the diagram, it can be observed that the temperature on the left and right sides of the dust hood keeps rising; when the height of the workshop is below 6.8 meters, the temperature is around $31^{\circ} \mathrm{C}$. However, due to the irregular timing of airflow discharged, the temperature of the high-temperature airflow above the plant will rise to about $35^{\circ} \mathrm{C}$; when it is close to the wall of the plant, the updraft cannot be eliminated in time, thus turning back down to produce a large vortex, resulting to a high concentration area appearing at the middle of the plant. Moreover, due to the suction of the dust hood and the large disturbance of the longitudinal airflow, the concentration of particulate matter in the right area of the middle part is significantly higher than that of the left part, and the concentration distribution is uneven.

The plant's pollutants are mainly due to the smoke and dust emitted by the taphole that cannot be removed in time by the dust hood. The particulate matter will escape from the dust hood with the airflow, and some particulate matter will be deflected to the north and discharged from the skylight on the north side. Since the particulate matter generated in the slag ditch is far away from the dust hood, it will follow the airflow and accumulate inside the workshop, and because the speed in the depth of the workshop is relatively low, it is difficult to discharge the particulate matter

The analysis of Figures 14 and 15 shows the influence of the vent on the airflow. When the air enters from the bottom window, part of it is taken away by the dust hood, and the other part is taken away from the skylight. However, the vent's wrong location will make it difficult for airflow to exit the skylight, causing particles to accumulate in the height of the plant. 


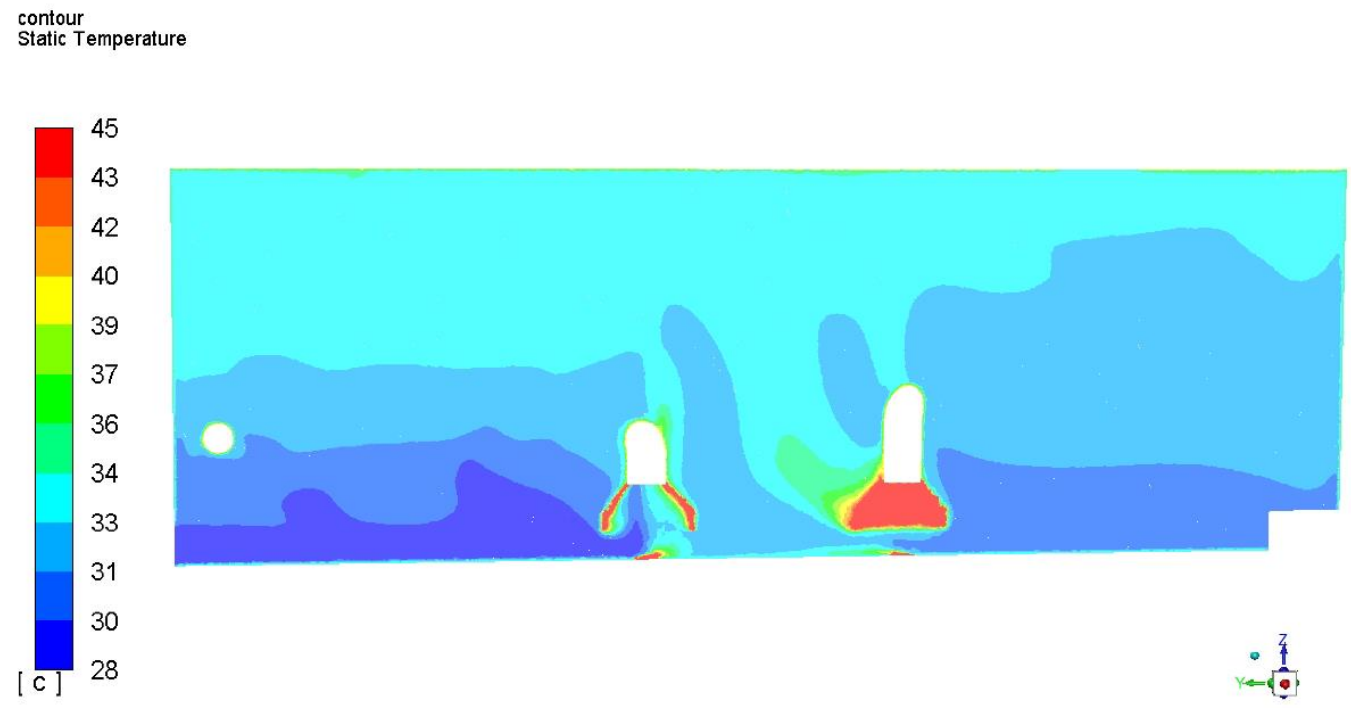

Fig.14 Cloud map of temperature in the center of the dust catcher

contour

DPM Concentration
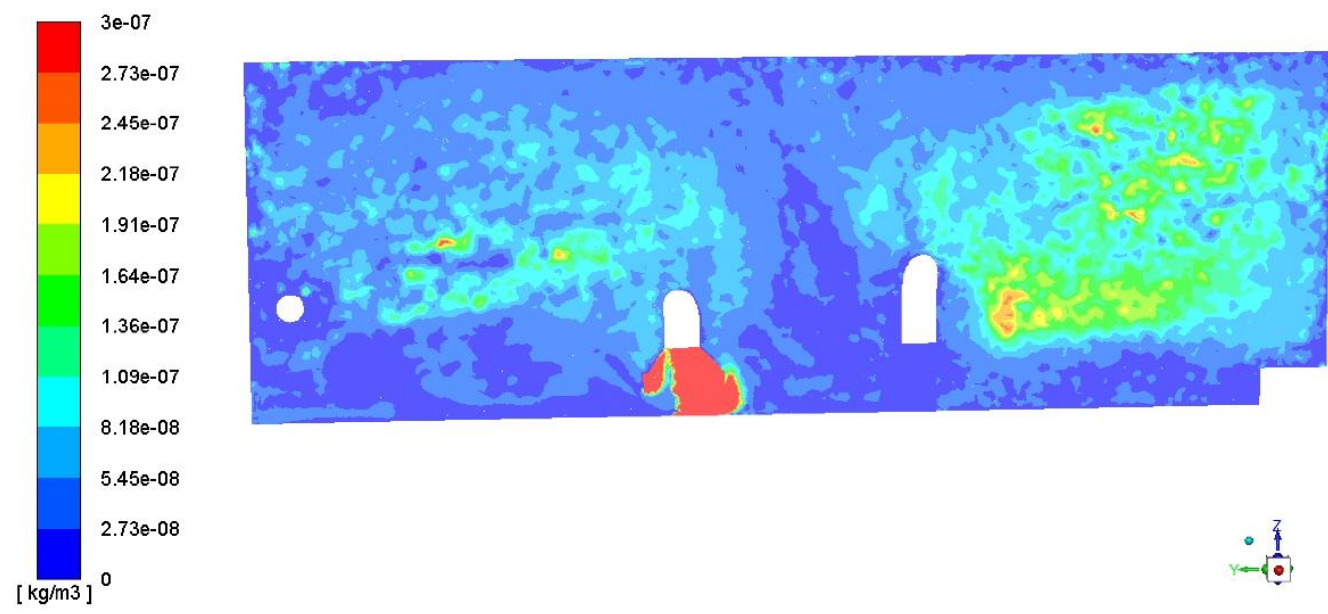

$\frac{7}{0}-\frac{7}{9}$

Fig.15 Cloud map of PM2.5 concentrations in the center of the dust catcher

The ventilation effect is related to two factors: the amount of fresh air sent in and the other is the form of airflow organization. The following uses the waste heat removal efficiency, the effective ventilation ratio, and the actual number of new air changes to evaluate the iron yard room's ventilation effect. The calculation results are shown in Tables 7, 8, and 9.

The PMV value is too large for workers, and the plant's waste heat is also a pollutant. Therefore, the waste heat removal efficiency is used to investigate the efficiency of energy utilization in the form of airflow organization (Zhu et al. 2010); this is defined as:

$$
\eta_{t}=\frac{t_{e}-t_{s}}{\overline{t_{a}}-t_{s}}
$$


449 Where $t_{e}$ is the exhaust air temperature, $t_{s}$ is the supply air temperature, and $450 \overline{t_{a}}$ is the average temperature of the working area.

Table 7 Waste heat removal efficiency

\begin{tabular}{cccc}
\hline $\begin{array}{c}\text { Exhaust air } \\
\text { temperature } \\
{ }^{\circ} \mathbf{C}\end{array}$ & $\begin{array}{c}\text { Exhaust air } \\
\text { temperature } \\
{ }^{\circ} \mathbf{C}\end{array}$ & $\begin{array}{c}\text { Average temperature of } \\
\text { the working area. } \\
{ }^{\circ} \mathbf{C}\end{array}$ & $\begin{array}{c}\text { Waste heat } \\
\text { removal efficiency }\end{array}$ \\
\hline 33.2 & 29 & 30 & 4.2 \\
\hline
\end{tabular}

452 This plant adopts the form of combining the local exhaust of the smoke hood with 453 natural ventilation. The exhaust air volume was increased to eliminate particulate matter, 454 prone to short-circuiting of the natural exhaust vents. Xing et al. (2018) proposed two 455 parameters, sufficient ventilation volume and effective ventilation ratio. When the 456 effective ventilation ratio is less than 1 , it indicates that the natural ventilation opening 457 is short-circuited; the definition is given as follows:

$$
G_{e}=\left|G_{j p}+G_{z p}\right|=G_{z j}
$$

$$
\eta_{e}=\left|G_{e} / G_{j p}\right|
$$

Where $G_{e}$ is the effective ventilation volume, $G_{j p}$ is the mechanical exhaust volume, $G_{z p}$ is the natural exhaust vent ventilation volume, $G_{z j}$ is the natural air inlet ventilation volume, and $\eta_{e}$ is the effective ventilation ratio.

Table 8 Effective ventilation ratio

\begin{tabular}{cccc}
\hline $\begin{array}{c}\text { Mechanical exhaust } \\
\text { volume } \mathbf{~ m}^{\mathbf{3}} / \mathbf{s}\end{array}$ & $\begin{array}{c}\text { Natural exhaust } \\
\text { vent ventilation } \\
\text { volume } \mathbf{~ m}^{\mathbf{3}} / \mathbf{s}\end{array}$ & $\begin{array}{c}\text { Natural air inlet } \\
\text { ventilation } \\
\text { volume } \mathbf{~ m}^{\mathbf{3}} / \mathbf{s}\end{array}$ & $\begin{array}{c}\text { Effective } \\
\text { ventilation ratio }\end{array}$ \\
\hline 110.25 & 201.55 & 308.89 & 2.8 \\
\hline
\end{tabular}

Luo et al. (2007) put forward the concept of actual fresh air changes. The number of fresh air changes is integrated into the sewage efficiency, taking into account the amount of fresh air sent into the room and the ventilation system's ability to remove pollutants. It is characterized by the frequency of pollutants discharged by the system in a steady-state, that is, the system's driving force to eliminate pollutants relative to a uniform mixing condition. The definition is as follows:

$$
n_{R O A C}=\varepsilon \cdot n_{O A C}=\frac{C_{e}-C_{S}}{\bar{C}-C_{S}} n_{O A C}
$$

$$
n_{O A C}=\frac{Q_{f}}{V}
$$

472 Where $C_{e}$ is the pollutant concentration at the exhaust outlet, $C_{s}$ is the pollutant 473 concentration at the air outlet, $\bar{C}$ is the average pollutant concentration in the room, $474 Q_{f}$ is the hourly fresh air volume, and $V$ is the room volume. 
Table 9 The actual number of fresh air changes

\begin{tabular}{cccccc}
\hline $\begin{array}{c}\text { Ventilation } \\
\mathbf{m}^{\mathbf{3}} / \mathbf{h}\end{array}$ & $\begin{array}{c}\text { Number of } \\
\text { fresh air } \\
\text { changes }\end{array}$ & $\begin{array}{c}\text { Air outlet } \\
\text { concentration } \\
\mathbf{m g} / \mathbf{~}^{\mathbf{3}}\end{array}$ & $\begin{array}{c}\text { Exhaust vent } \\
\text { concentration } \\
\mathbf{m g} / \mathbf{~ m}^{\mathbf{3}}\end{array}$ & $\begin{array}{c}\text { Respiratory } \\
\text { zone } \\
\text { concentration } \\
\mathbf{m g} / \mathbf{~ m}^{\mathbf{3}}\end{array}$ & $\begin{array}{c}\text { Actual fresh } \\
\text { air changes }\end{array}$ \\
\hline 1112001.512 & 7.9 & 0.03 & 0.155 & 0.0618 & 31 \\
\hline
\end{tabular}

476

477

478

479

480

481

482

483

484

485

486

487

488

489

490

491

492

493

494

495

496

497

498

499

500

501

502

503

504

505

506

507

\section{Conclusion}

This paper selected a typical blast furnace tapping workshop and conducted on-site measurement to obtain the characteristics of the wind speed distribution, temperature distribution, and soot concentration distribution in the workshop during the tapping period; it established a numerical simulation model based on computational fluid dynamics and further analyzed the performance of the taphole smoke exhaust system. Based on the result and finding, the paper draws the following conclusions and recommendations:

(1) The temperature in the workers' breathing zone in the entire plant is mostly below $31^{\circ} \mathrm{C}$, while the temperature in the vicinity of the slag ditch, iron ditch, and blast furnace is around $33^{\circ} \mathrm{C}$, with the highest temperature reaching $40^{\circ} \mathrm{C}$, which is still very high. Through the evaluation of the thermal comfort of the breathing area by PMV, the comfort is low, and it feels scorching; the concentration of PM2.5 is mostly below $80 \mu \mathrm{g} / \mathrm{m}^{3}$, for workers, and the conditions of the entire breathing area are acceptable;

(2) The plant's main problem is that when the 2\# iron ditch is working, the dust hood is at the front of the plant. Due to longitudinal airflow interference and obstacles, high temperatures usually appear at the rear of the plant, especially when the right part of the slag ditch reaches about $33^{\circ} \mathrm{C}$, making people feel uncomfortable. The deepest area has a high concentration of particulate matter. Also, because the plant is relatively high and the airflow organization is unreasonable, it is difficult for particulate matter to be discharged from the skylight, which accumulates in the middle of the plant, and makes the temperature very high.

Given the problem of high temperature and particulate matter accumulation on the right side of the blast furnace in the plant, the paper recommends the following actions:

(1) To consider increasing the number of vents deep inside the plant to make the airflow in the workshop's depth smoother.

(2) Regarding particulate matter accumulation in mid-air, it is observed due to the airflow organization being unreasonable. The best option in addressing this problem is to change the area, direction, location, and other parameters of the vents to allow the airflow organization to more reasonable. Another option is to consider revamping the dust hood to make the plant cleaner. 


\section{Declarations}

Ethics approval and consent to participate

$510 \quad$ Not applicable

\section{Consent for publication}

$512 \quad$ Not applicable

Availability of data and materials

All data generated or analysed during this study are included in this published article.

\section{Competing interests}

516 The authors declare that they have no competing interests

\section{Acknowledgments}

518 This work was supported by the National Key Research and Development Plan of 519 the Ministry of Science and Technology of China (Grant No. 2018YFC0705300) and 520 the Open Fund Project for State Key Laboratory of Iron and Steel Industry 521 Environmental Protection (Grant No. YZC2019Ky03).

\section{Authors' contributions}

Hui Wang: Conceptualization, Methodology, Writing - original draft, Supervision, Project administration, Funding acquisition. Tianying Wang: Software, Methodology, Data curation, Formal analysis, Writing - original draft, Liuchan Liu: Validation, Formal analysis, Writing - review \& editing, Zhengwei Long :Methodology, Writing review \& editing, Pu Zhang: Writing - review \& editing.

\section{Reference}

Biswas MJ, Koparkar AR, Joshi MP, Hajare ST, Kasturwar NB (2014) A study of morbidity pattern among iron and steel workers from an industry in central India. Indian Journal of Occupational \& Environmental Medicine18(3):122-128. doi: 10.4103/0019-5278.146909.

Cao ZX, Zhai C, Wang Y, Zhao TT, Wang HY (2020) Flow characteristics and pollutant removal effectiveness of multi-vortex ventilation in high pollution emission industrial plant with large aspect ratio. Sustainable Cities and Society 54. https://doi.org/10.1016/j.scs.2019.101990.

Chen CM, Lai DY, Chen QY (2020) Energy analysis of three ventilation systems for a large machining plant. Energy and Buildings 110272. https://doi.org/10.1016/j.enbuild.2020.110272.

Chinese Research Academy of Environmental Sciences (2012) Ambient air quality standards. China Environmental Science Press (in Chinese).

Fahed AK, Ozkaymak M, Ahmed S (2018) Impacts of heat exposure on workers' health and performance at steel plant in turkey. Engineering Science and Technology 21(4):745-752. https://doi.org/10.1016/j.jestch.2018.05.005. 
Huang YQ, Lu K, Wang Y, Jiang C, Cao L, Liu Y (2019) Study on limit flow ratio method for a lateral exhaust hood above high-temperature buoyant jets. Sustainable Cities and Society https://doi.org/10.1016/j.scs.2019.101969.

Krishnamurthy M, Ramalingam P, Perumal K, et al (2017) Occupational heat stress impacts on health and productivity in a steel industry in southern India. Safety and Health at Work. https://doi.org/10.1016/j.shaw.2016.08.005.

Lau J, Chen QY (2006) Floor-supply displacement ventilation for workshops. Building and Environment 42(4). https://doi.org/10.1016/j.buildenv.2006.01.016.

Li X-T, Ma X-J, Shao X-L (2016) Challenges to ventilation and opportunities in the period of the 13th five-year plan in China. Refrigeration and Air Conditioning 30(03):237-244 (in Chinese). doi:10.3969/j.issn.1671-6612.2016.03.001.

Liu D-Q, Ji X-L (2006) Study on particulate pollution characteristics of typical sources in iron and steel works. Environmental Science and Management 31(4):53-55 (in Chinese). doi:10.3969/j.issn.1673-1212.2006.04.017.

Liu K, Yang X-D, Xiao Y (2015) Emission characteristics of particulate matter (PM2.5) in iron and steel production and pollution control measures. World Metals (in Chinese).

Liu YI (2016) The efficient dust capture technology simulation research of blast furnace iron field. Dissertation, Huazhong University of Science and Technology (in Chinese). doi:10.7666/d.D01076987.

Liu YL (2015) The measurement and numerical simulation of tall industrial plant in hot authentic tunnel ventilation. Dissertation, Xi'an University of Architecture and Technology (in Chinese). doi:10.7666/d.D714152.

Luo Z-W, Zhao J-N (2007) Revised index for ventilation performance evaluation: number of real outdoor air exchanges. Journal of Harbin Institute of Technology 39(6) (in Chinese). doi:10.3321/j.issn:0367-6234.2007.06.018.

Ma WW, Liu WX, Li LQ, Huang GJ, Su B, Yu C (2015) Numerical simulation of unsteady-state particle dispersion in ferroalloy workshop. Indoor and Built Environment 24(8):1069-1081. doi:10.1177/1420326X15590256.

Ou S-Y, Liu H-Q, Zhang Q, Mi L-H, Zhu K-Y, Chen F (2018) Simplified calculation method of the predicted mean thermal sensation index PMV. Building Energy Efficiency 46(07):13-16 (in Chinese). doi:10.3969/j.issn.1673-7237.2018.07.003.

Shih TH, Liou WW, Shabbir A, Yang ZG, Zhu J (1995) A new k- $\varepsilon$ eddy viscosity model for high Reynolds number turbulent flows. Computers \& Fluids 24(3):227-238. doi:10.1016/0045-7930(94)00032-t.

Su YX, Wan X (2011) CFD simulation and retrofit of natural ventilation in a steel workshop. Advanced Materials Research 383-390:6608-6613. https://doi.org/10.4028/www.scientific.net/AMR.383-390.6608.

Tang L, Xue X, Jia M, Jing H, Wang, S (2020) Iron and steel industry emissions and contribution to the air quality in china. Atmospheric Environment237:117668. https://doi.org/10.1016/j.atmosenv.2020.117668. 
Wang H, Zhang P (2021) Simulation study on diffusion and collection characteristics of high temperature smoke and dust in blast furnace cast house. Environmental Engineering (in Chinese).

Wang X, Lei Y, Yan L, Liu T, Zhang Q, He K (2019) A unit-based emission inventory of $\mathrm{SO}_{2}, \mathrm{NO}_{\mathrm{X}}$ and $\mathrm{PM}$ for the Chinese iron and steel industry from 2010 to 2015. Science of The Total Environment 676(AUG.1):18-30. https://doi.org/10.1016/j.scitotenv.2019.04.241.

Wang Y, Huang Y-Q, Liu J-P, Xiao P, Wen F (2013) Flow field of high-temperature gases and exhaust hood optimization in ironmaking plant. Architectural \& Environmental Engineering 162-166 (in Chinese). doi:CNKI:SUN:JIAN.0.2013S1-037.

Wang Y, Meng XJ, Yang XN, Liu JP (2014) Influence of convection and radiation on the thermal environment in an industrial building with buoyancy-driven natural ventilation. Energy \& $\begin{array}{llll}\text { 75:394-401. } \\ \text {. }\end{array}$ https://doi.org/10.1016/j.enbuild.2014.02.031.

Wang Y, Huang Y-Q, Yang Y, Zhang H-Y (2015) Flow and control method of hightemperature dusty airflow in large industrial building. Science China Press (18):1690 (in Chinese). doi:10.1360/N972015-0003.

Wiriyasart S, Naphon P (2019) Numerical study on air ventilation in the workshop room with multiple heat sources. Case Studies in Thermal Engineering 13. https://doi.org/10.1016/j.csite.2019.100405.

Xing X, Meng X-J, Gou H-S (2018) Combined operation with thermal ventilation and mechanical exhaust in an industrial thermal plant. Building Energy \& Environment 37(2):65-70 (in Chinese). doi:CNKI:SUN:JZRK.0.2018-02-016

Xue YF, Su YX (2011) The improvement of natural ventilation in an industrial workshop by solar chimney. International Conference on Computer Distributed Control \& Intelligent Environmental Monitoring. IEEE. doi:10.1109/CDCIEM.2011.517.

Yang XH, Long Y, Meng LZ, Jin YH (2015) Natural ventilation design and optimization of large-scale industrial workshop. Advanced Materials Research 10651069:2137-2140. https://doi.org/10.4028/www.scientific.net/AMR.10651069.2137

Zhang J, Long ZW, Liu W, Chen QY (2016) Strategy for studying ventilation performance in factories. Aerosol \& Air Quality Research 16(2):442-452. https://doi.org/10.4209/aaqr.2014.09.0210

Zhang JP, Johnson W, Plikas T(2017) Application of computational fluid dynamics for solving ventilation problems in metallurgical industrial processes. International Journal of Ventilation 16:3, 200-212, DOI: 10.1080/14733315.2017.1299516

Zhao B, Yang CQ, Yang XD, Liu SK (2008) Particle dispersion and deposition in ventilated rooms: testing and evaluation of different Eulerian and Lagrangian $\begin{array}{llll}\text { models. Building \& Environment 43(4):388-397. } & \text { \& }\end{array}$ https://doi.org/10.1016/j.buildenv.2007.01.005 
629 Zhou Y, Wang MY, Wang MN, Wang Y (2019) Predictive accuracy of Boussinesq 630 approximation in opposed mixed convection with a high-temperature heat source 631 inside a building. Building \& Environment 144:349-356. 632 https://doi.org/10.1016/j.buildenv.2018.08.043

633 Zhu Y-X (2010) Built Environment. China Architecture \& Building Press (in Chinese). 634 Zou S-H, Zhang D-C, Li K-Q (2005) Reformation of hot environment of semi-closed 635 heat-source workshop by natural ventilation. Mining and Metallurgical 636 Engineering 25(002):81-84 (in Chinese). doi:10.3969/j.issn.0253$637 \quad 6099.2005 .02 .024$ 


\section{Figures}
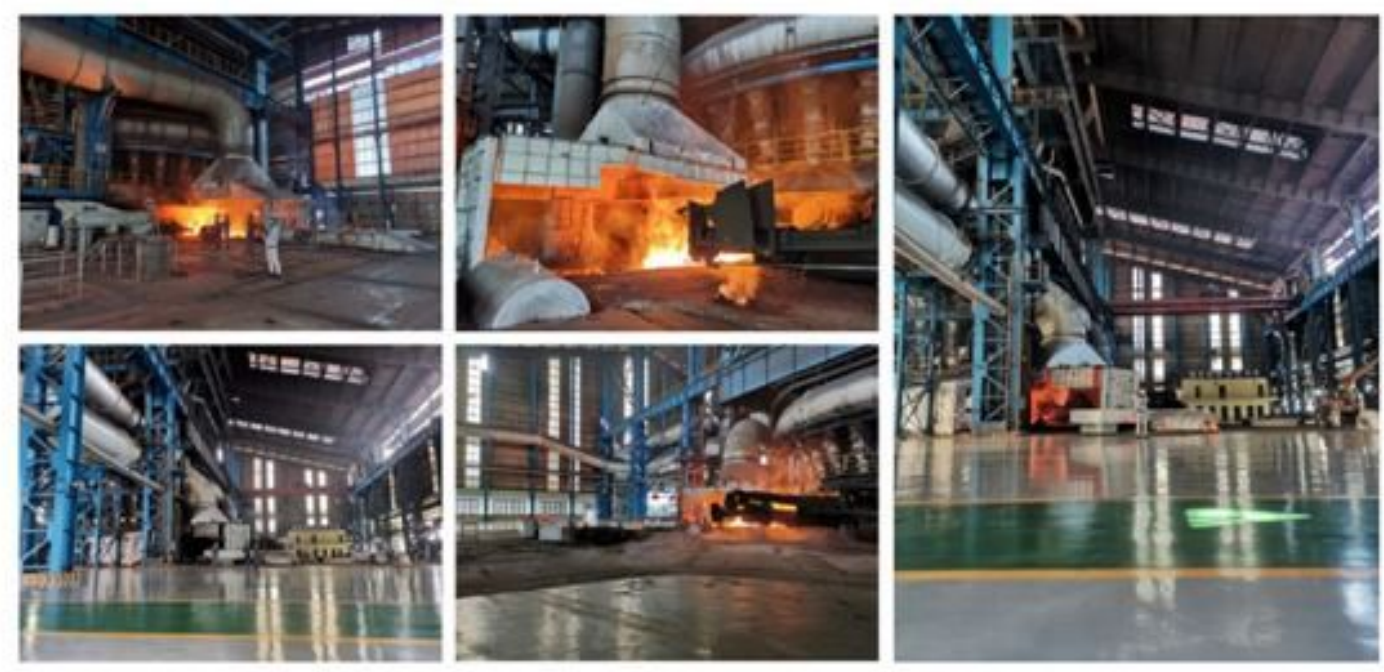

(a) Interior view of the workshop

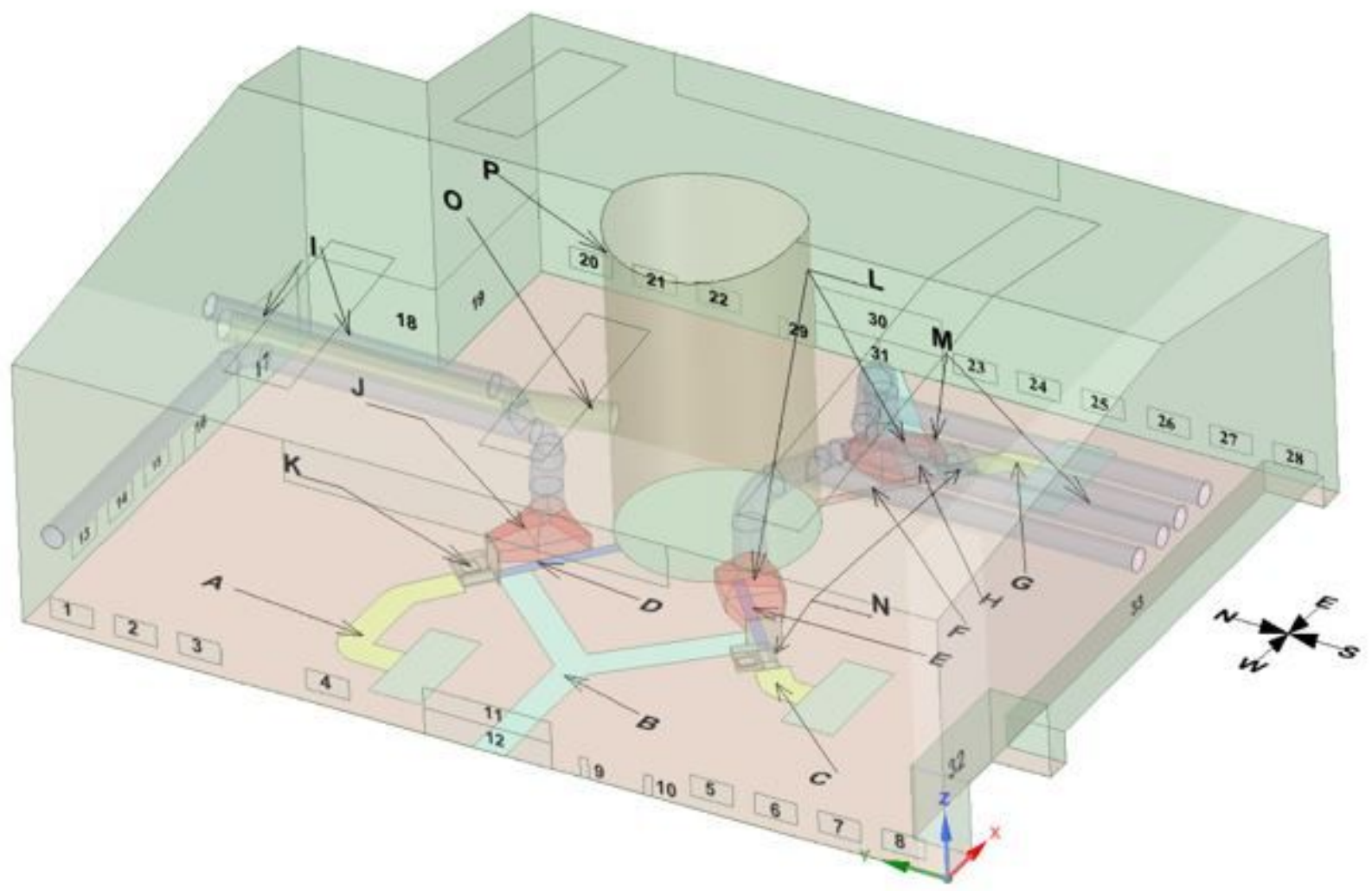

(b) 3D model of the workshop

Figure 1

Layout and main features of the iron workshop 


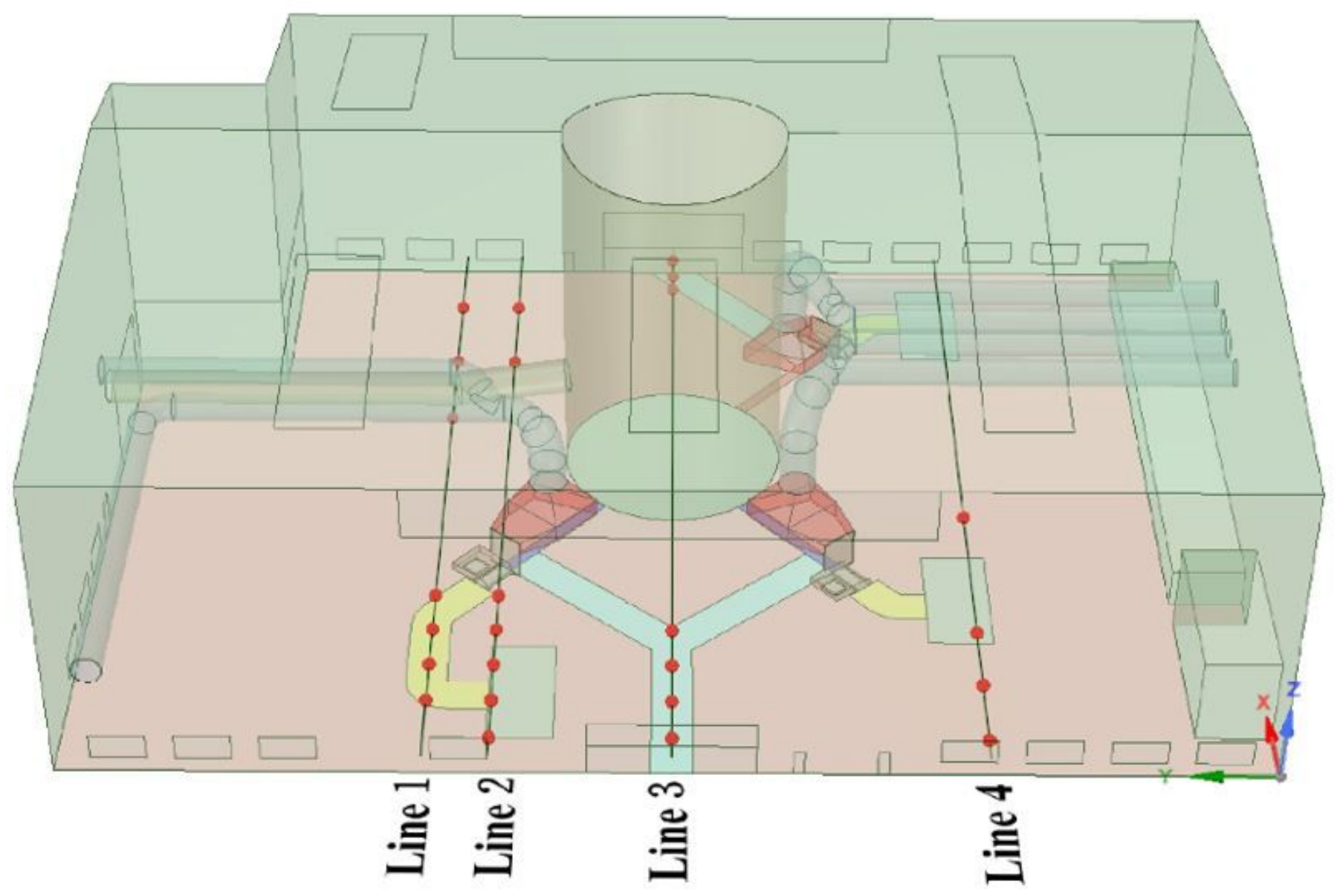

Figure 2

Schematic diagram of the site measurement location 


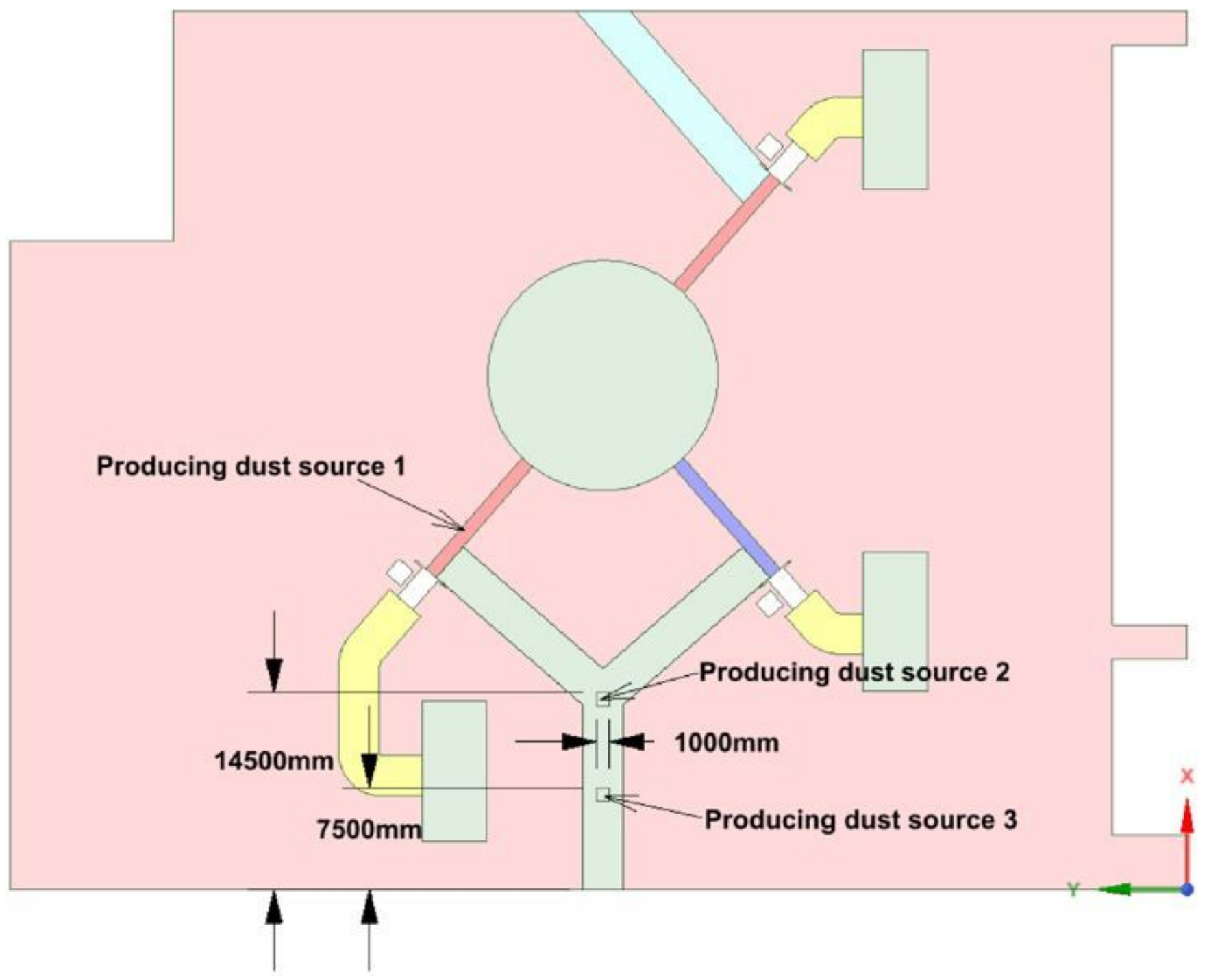

Figure 3

Dust production point layout 


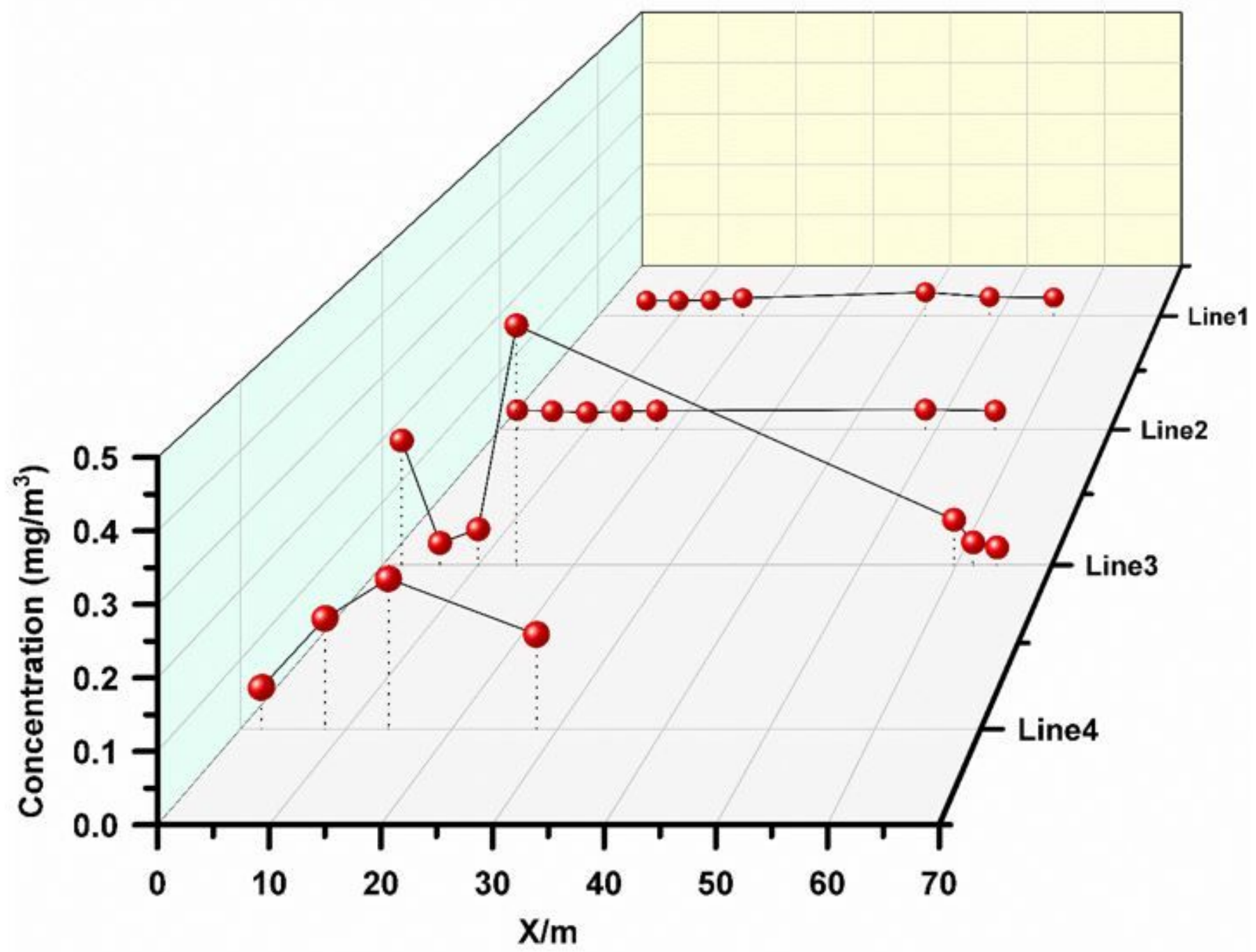

Figure 4

Distribution of PM2.5 concentration 


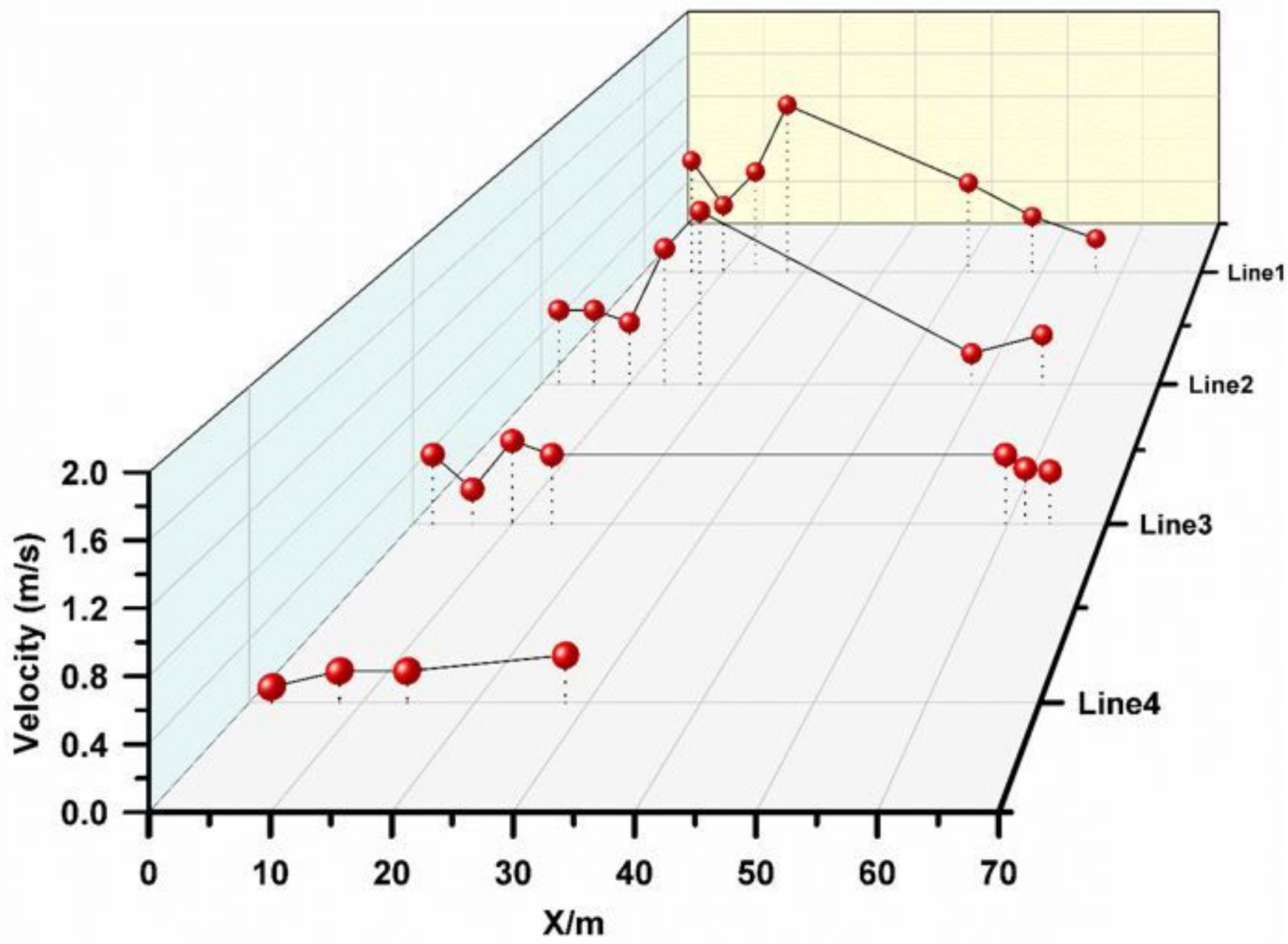

Figure 5

The velocity distribution 


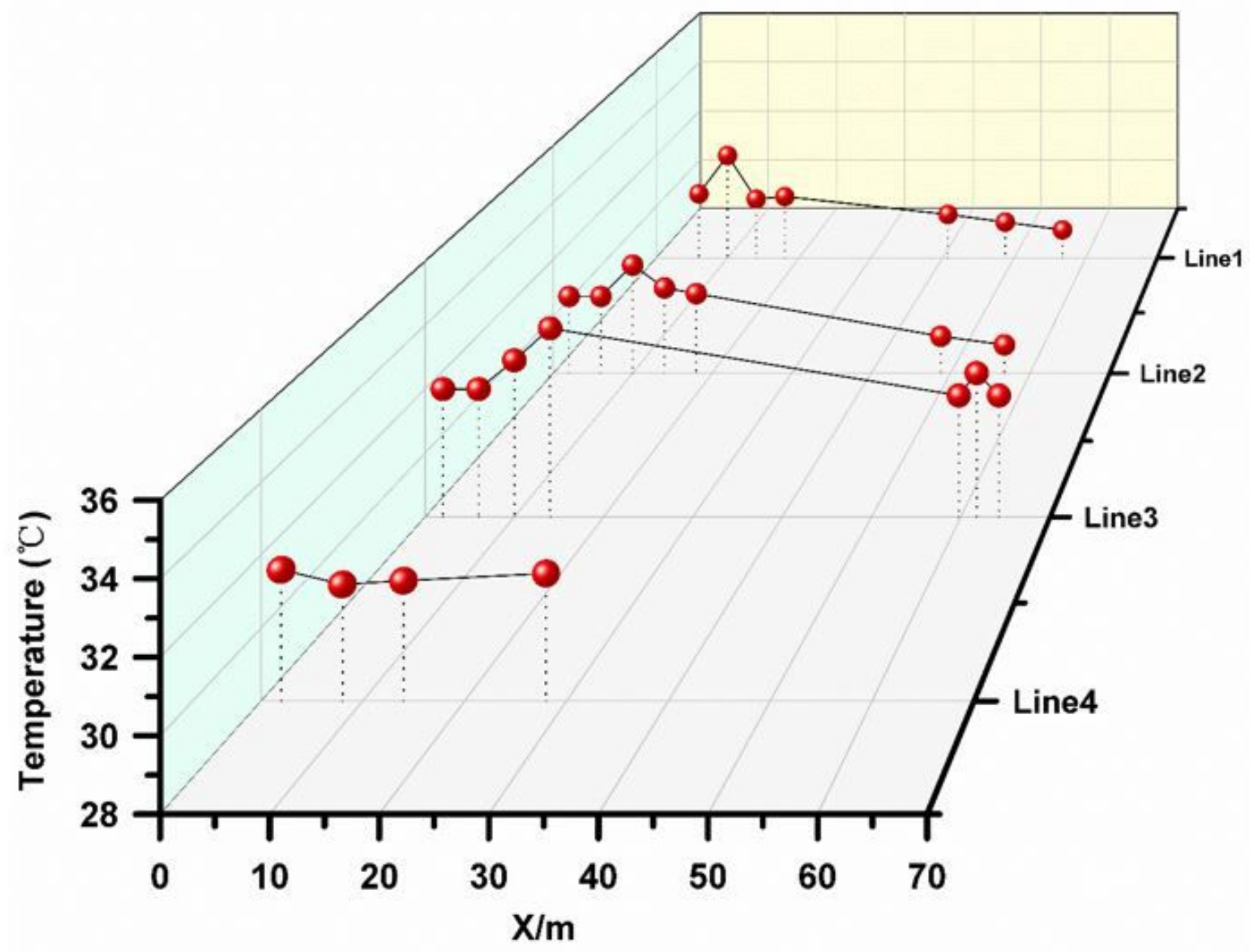

Figure 6

The temperature distribution 


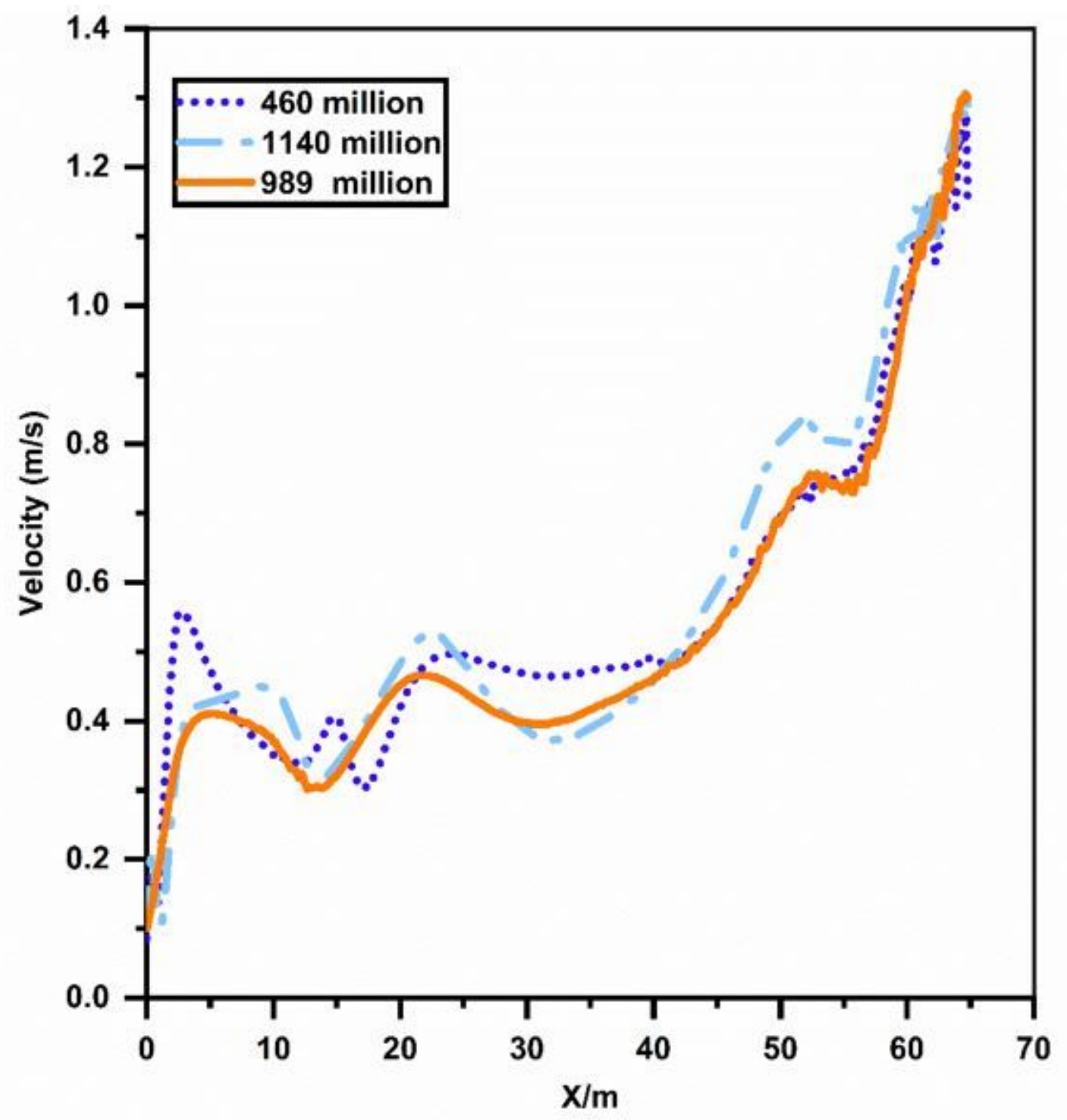

Figure 7

Grid independence verification 

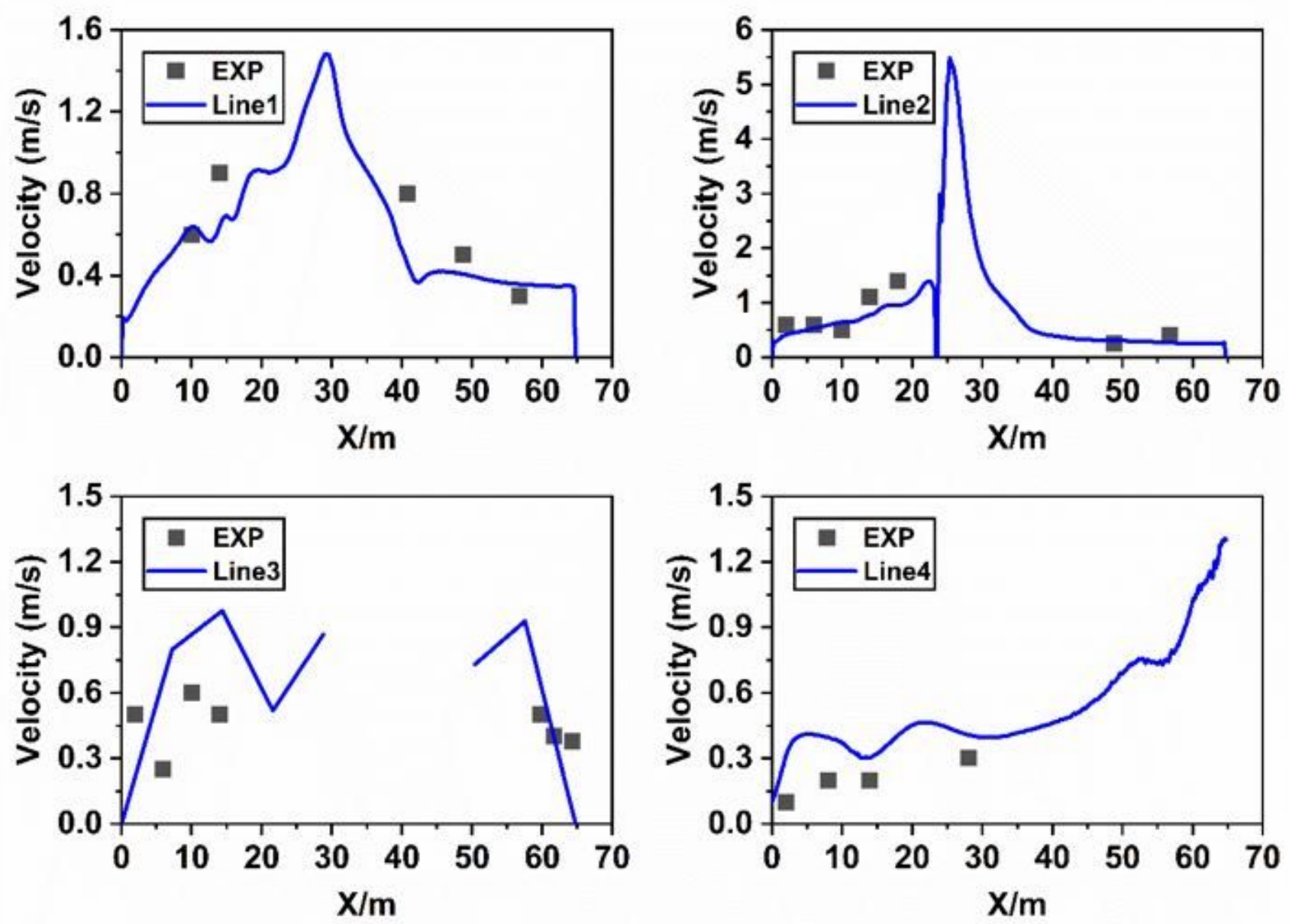

Figure 8

Comparison of the simulated air velocity with the experimental data on Line1 to Line4 

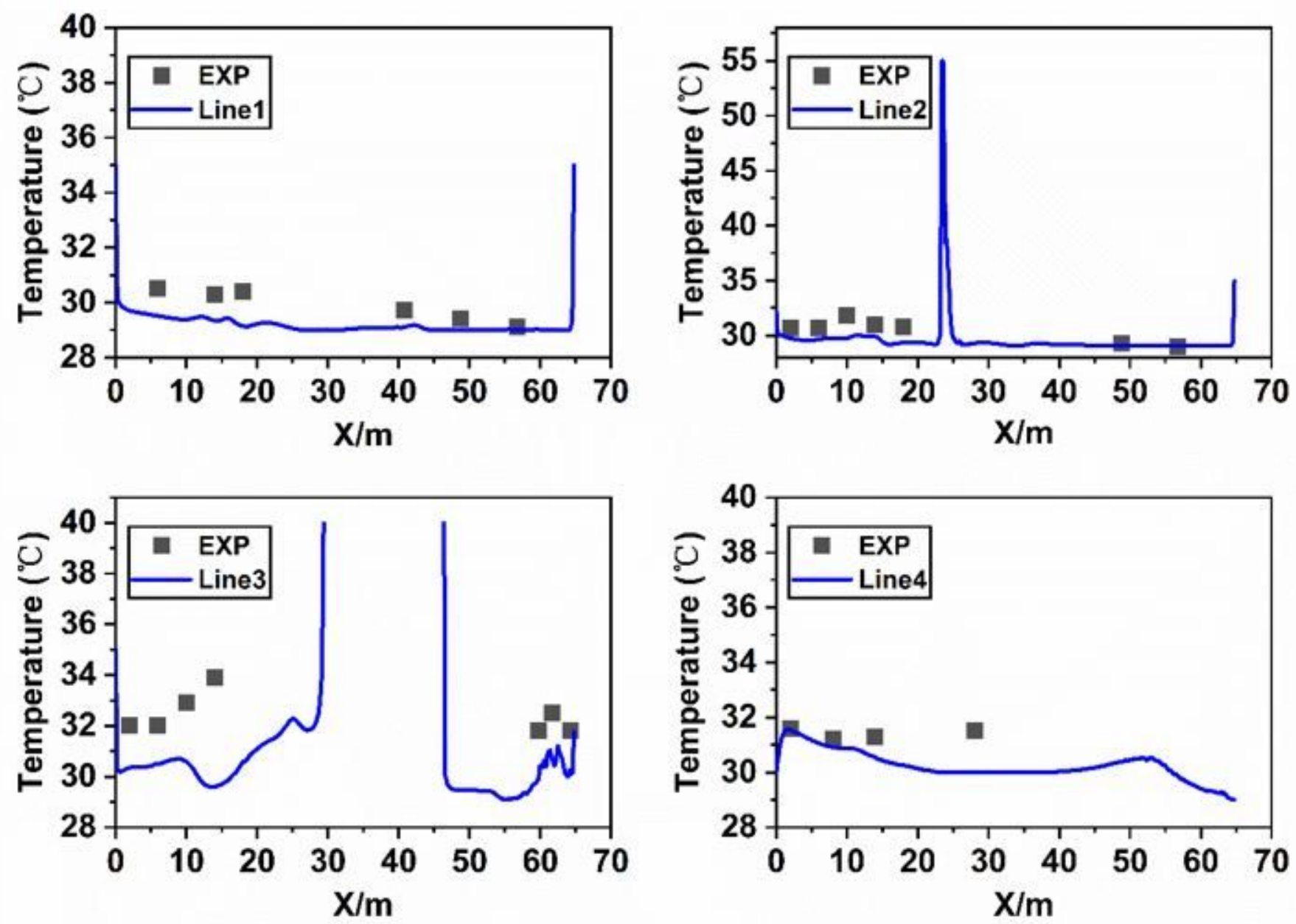

Figure 9

Comparison of the simulated air temperature with the experimental data on Line 1 to Line4 

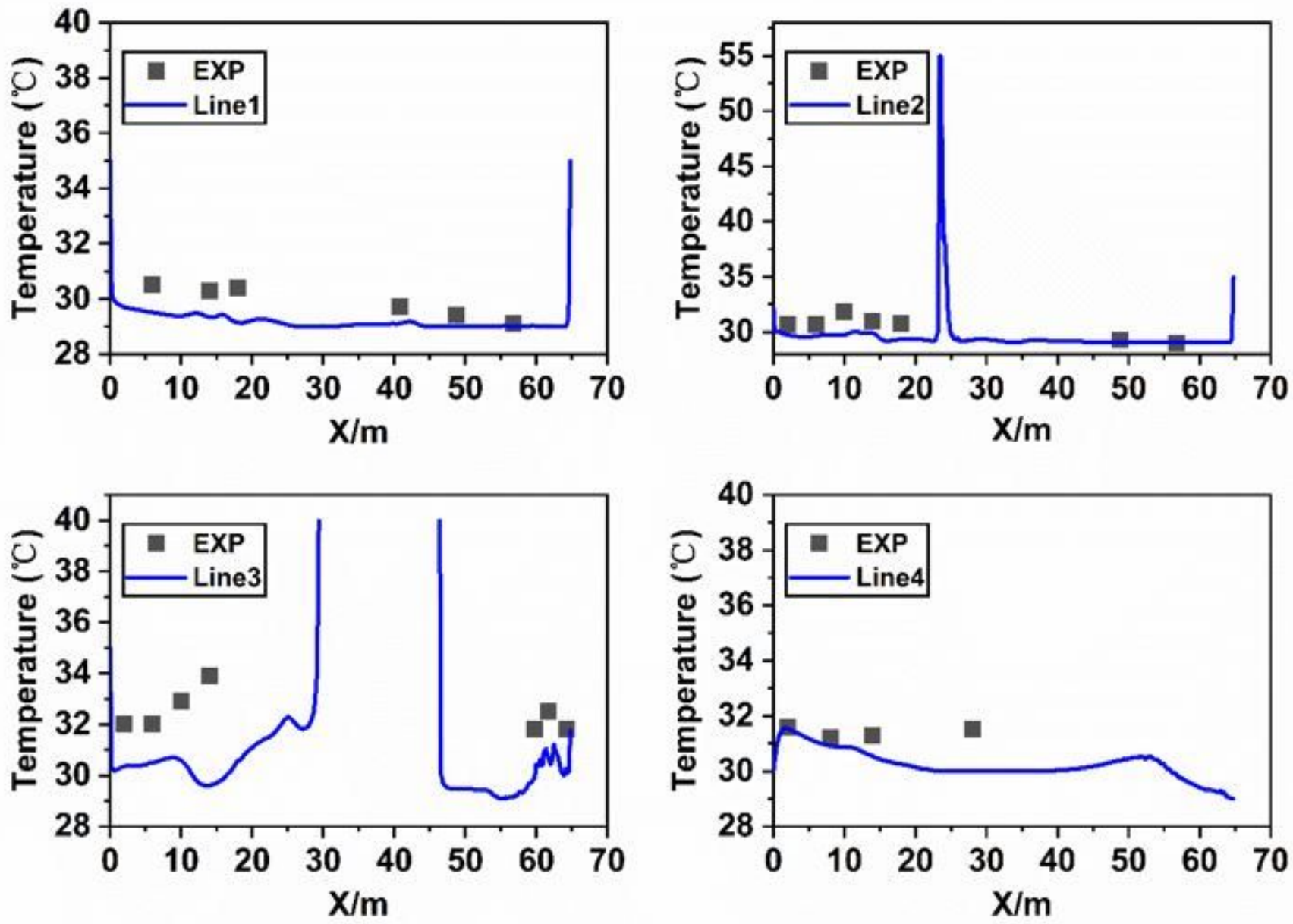

Figure 10

Comparison of the simulated PM2.5 concentration with the experimental data on Line1 to Line4 

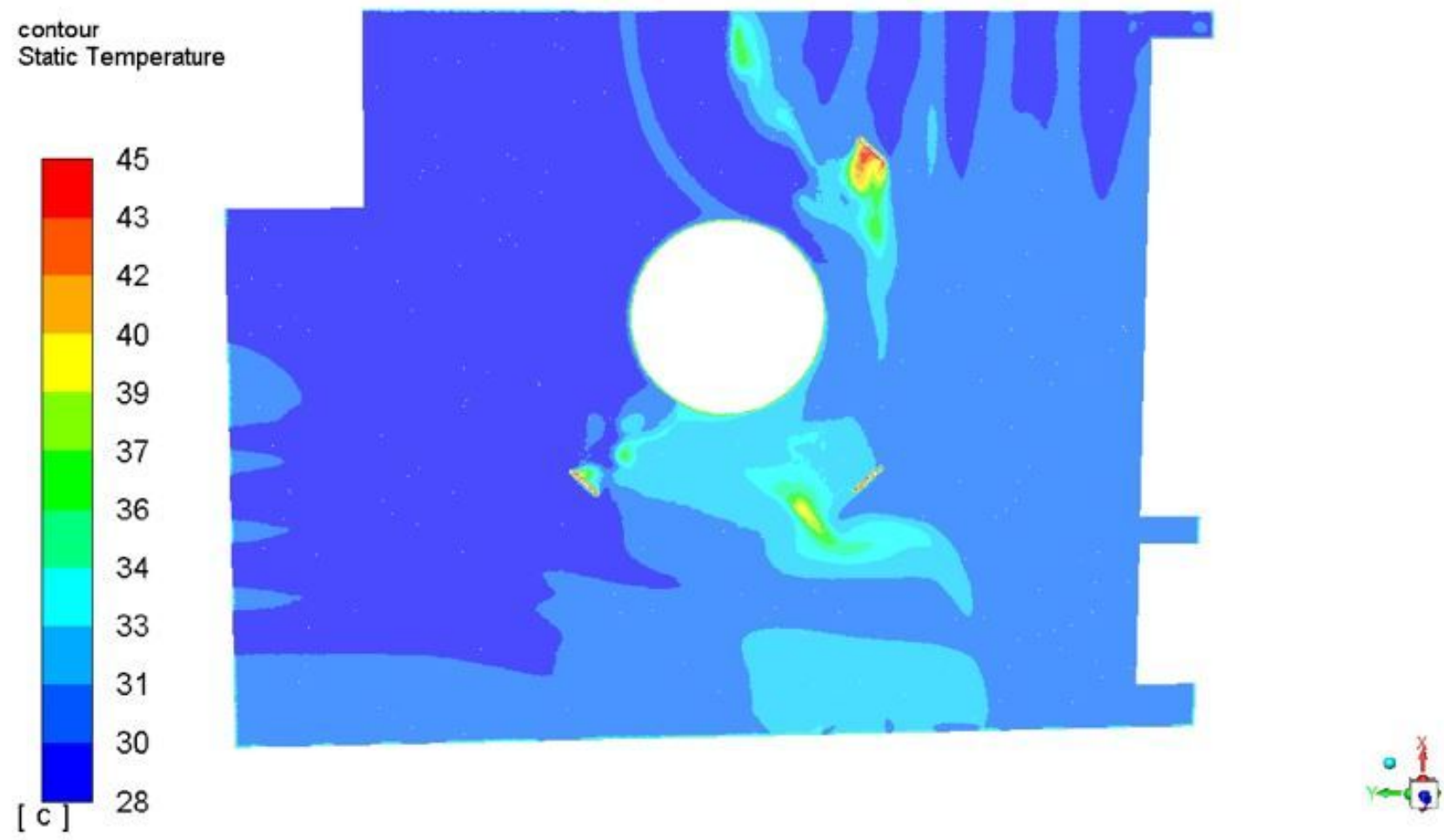

Figure 11

The temperature cloud map of the $z=1.5 \mathrm{~m}$ plane 

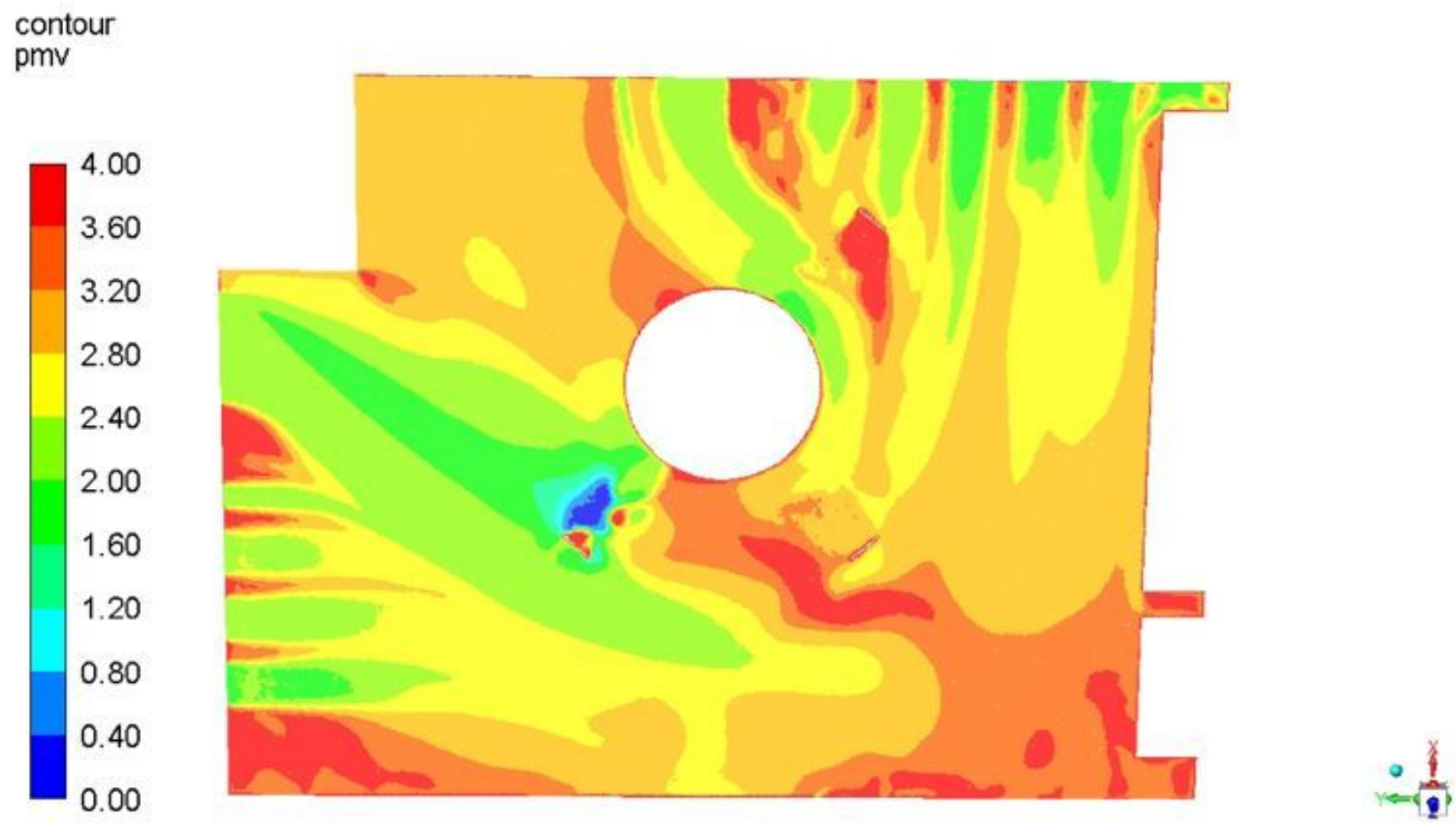

Figure 12

PMV value of the $z=1.5 \mathrm{~m}$ plane

contour

DPM Concentration
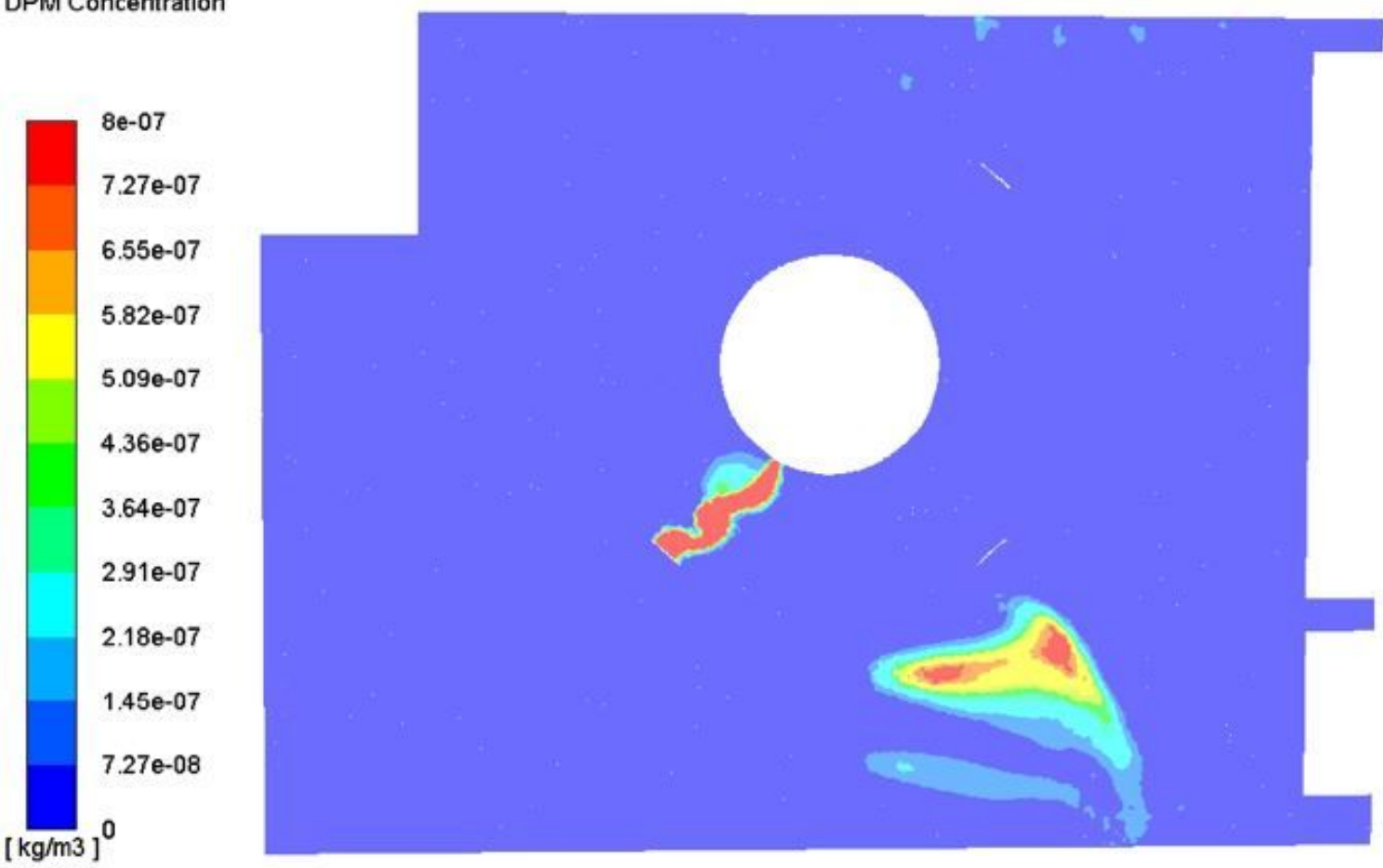


\section{Figure 13}

The PM2.5 concentration cloud map of the $z=1.5 \mathrm{~m}$ plane

contour

Static Temperature
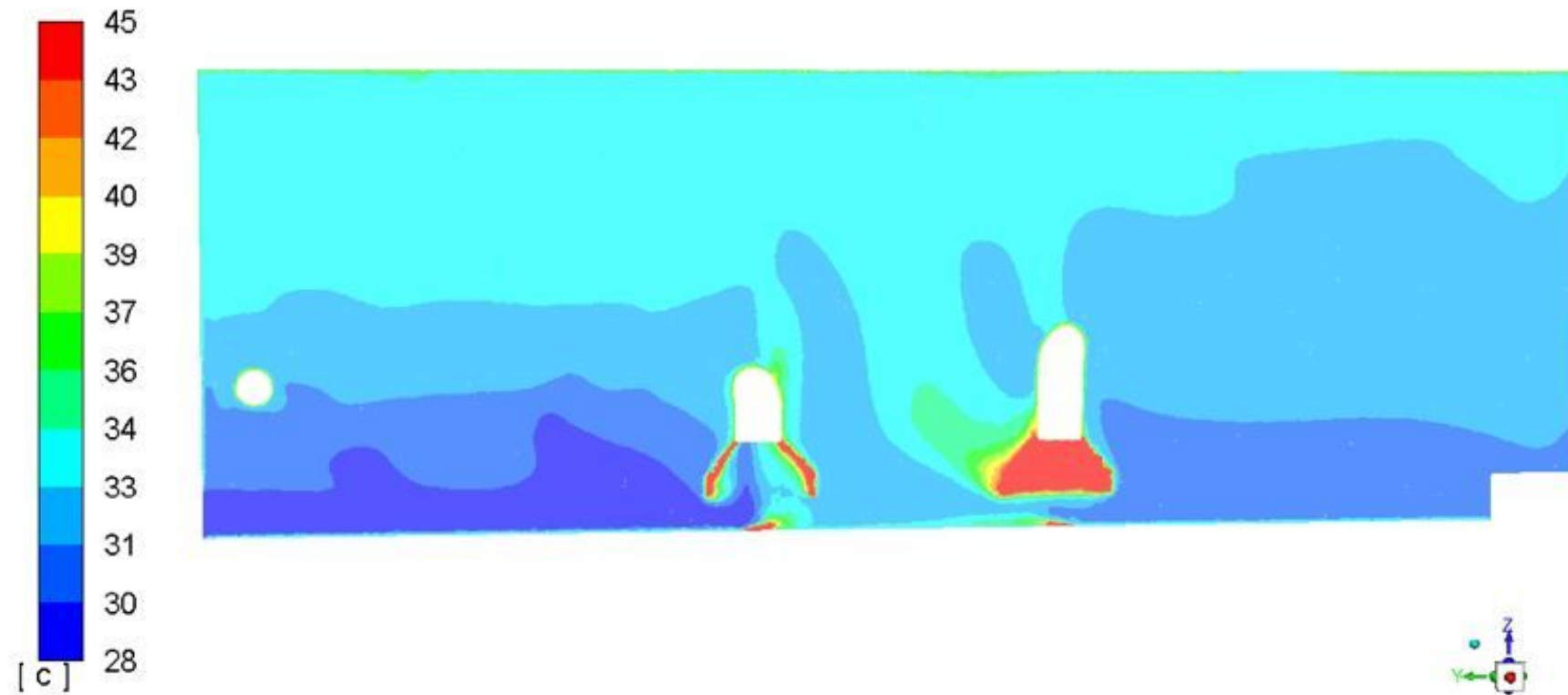

30 8

\section{$=\frac{7}{4}=\frac{7}{9}$}

\section{Figure 14}

Cloud map of temperature in the center of the dust catcher contour
DPM Concentration
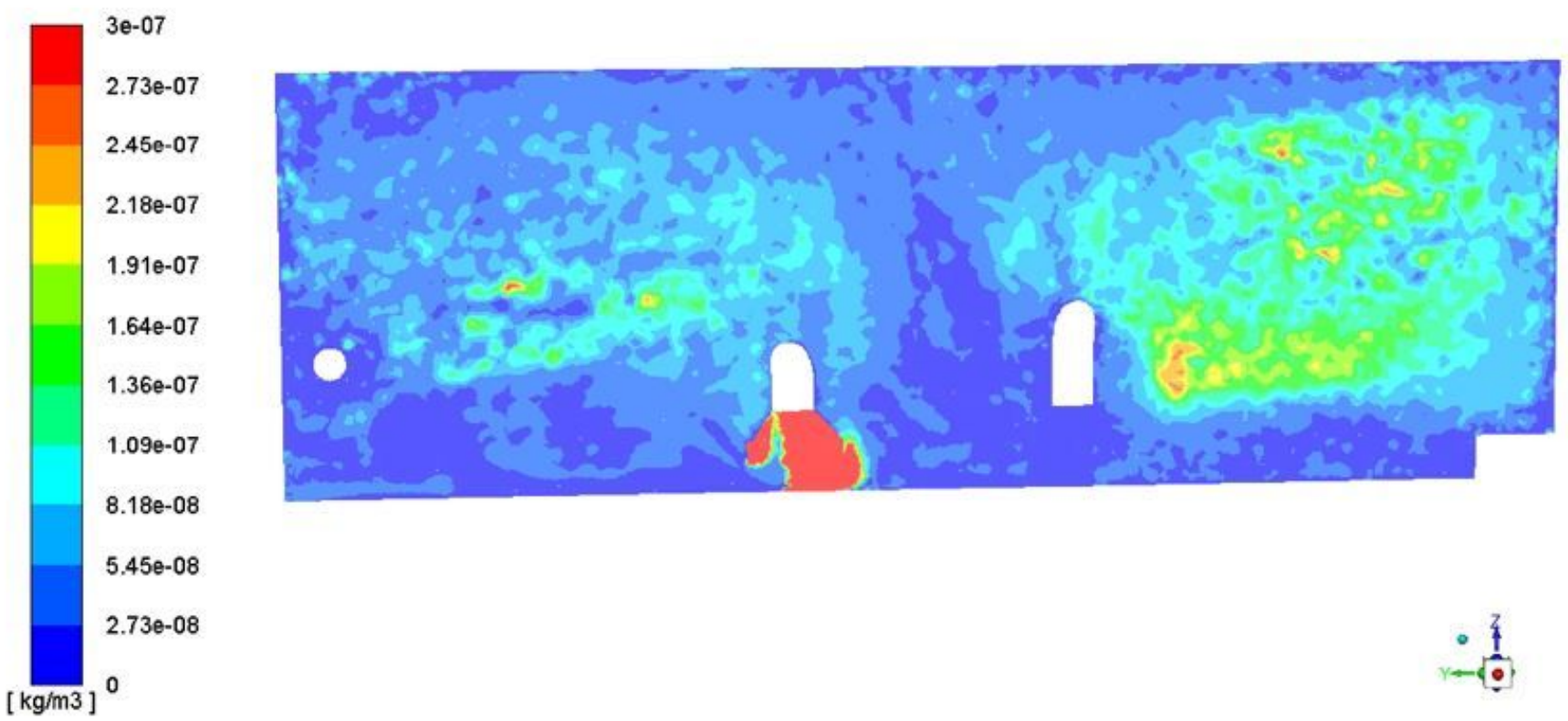

$45 e-08$

$2.73 e-08$ 
Figure 15

Cloud map of PM2.5 concentrations in the center of the dust catcher 